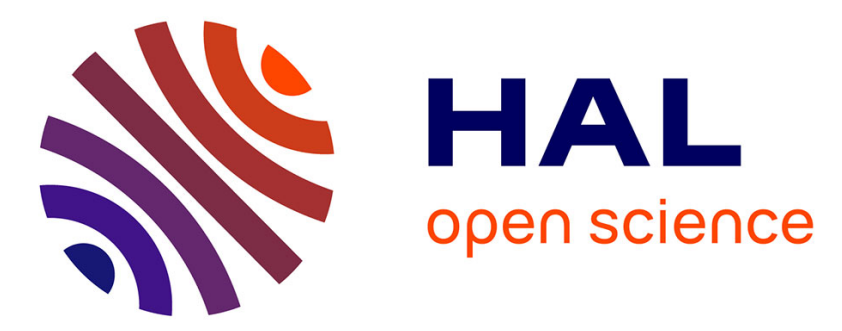

\title{
Comparative anatomy and phylogenetic contribution of intracranial osseous canals and cavities in armadillos and glyptodonts (Xenarthra, Cingulata)
}

Kévin Le Verger, Laureano R González Ruiz, Guillaume Billet

\section{> To cite this version:}

Kévin Le Verger, Laureano R González Ruiz, Guillaume Billet. Comparative anatomy and phylogenetic contribution of intracranial osseous canals and cavities in armadillos and glyptodonts (Xenarthra, Cingulata). Journal of Anatomy, 2021, pp.1-30. 10.1111/joa.13512 . hal-03291344

\section{HAL Id: hal-03291344 \\ https://hal.sorbonne-universite.fr/hal-03291344}

Submitted on 19 Jul 2021

HAL is a multi-disciplinary open access archive for the deposit and dissemination of scientific research documents, whether they are published or not. The documents may come from teaching and research institutions in France or abroad, or from public or private research centers.
L'archive ouverte pluridisciplinaire HAL, est destinée au dépôt et à la diffusion de documents scientifiques de niveau recherche, publiés ou non, émanant des établissements d'enseignement et de recherche français ou étrangers, des laboratoires publics ou privés. 


\title{
Comparative anatomy and phylogenetic contribution of intracranial osseous canals and cavities in armadillos and glyptodonts (Xenarthra, Cingulata)
}

\author{
Kévin Le Verger ${ }^{1}$ (1) | Laureano R. González Ruiz ${ }^{2}$ | Guillaume Billet ${ }^{1}$
}

${ }^{1}$ Museum national d'Histoire naturelle, Centre de Recherche en Paléontologie Paris, UMR 7207 CR2P MNHN/CNRS/ UPMC, Sorbonne Universités, Paris, France

${ }^{2}$ Laboratorio de Investigaciones en Evolución y Biodiversidad (LIEB-FCNyCS sede Esquel, UNPSJB) y Centro de Investigaciones Esquel de Montaña y Estepa Patagónica (CIEMEP), CONICET, Universidad Nacional de La Patagonia San Juan Bosco (UNPSJB), Chubut, Argentina

\section{Correspondence}

Kévin Le Verger, Museum national d'Histoire naturelle, Centre de Recherche en Paléontologie - Paris, UMR 7207 CR2P MNHN/CNRS/UPMC, Sorbonne Universités, Paris, France.

Email: kevin.le-verger@edu.mnhn.fr.

\begin{abstract}
The evolutionary history of the Cingulata, as for many groups, remains a highly debated topic to this day, particularly for one of their most emblematic representatives: the glyptodonts. There is no consensus among morphological and molecular phylogenies regarding their position within Cingulata. As demonstrated by recent works, the study of the internal anatomy constitutes a promising path for enriching morphological matrices for the phylogenetic study of armadillos. However, internal cranial anatomy remains understudied in the Cingulata. Here we explored and compared the anatomy of intracranial osseous canals and cavities in a diverse sample of extant and extinct cingulates, including the earliest well-preserved glyptodont crania. The virtual 3D reconstruction (using X-ray microtomography) of selected canals, that is, the nasolacrimal canal, the palatine canal, the sphenopalatine canal, the canal for the frontal diploic vein, the transverse canal, the orbitotemporal canal, the canal for the capsuloparietal emissary vein and the posttemporal canal, and alveolar cavities related to cranial vascularization, innervation or tooth insertion allowed us to compare the locations, trajectories, and shape of these structures and to discuss their potential interest for cingulate systematics. We tentatively reconstructed evolutionary scenarios for eight selected traits related to these structures in which glyptodonts often showed a close resemblance to pampatheres, to the genus Proeutatus, and/or to chlamyphorines. This latter pattern was partly congruent with recent molecular hypotheses, but more research is needed on these resemblances and on the potential effects of development and allometry on the observed variations. Overall, these comparisons have enabled us to highlight new anatomical variation that may be of great interest to further explore the evolutionary history of cingulates and the origins of glyptodonts on a morphological basis.
\end{abstract}

\section{KEYWORDS}

alveolar cavities, cingulata, comparative anatomy, cranial canals, evolutionary scenarios, glyptodont, phylogeny 


\section{1 | INTRODUCTION}

The peculiar morphology of xenarthrans, which include armadillos (Cingulata), sloths (Folivora), and anteaters (Vermilingua), has aroused the curiosity of anatomists since the end of the 18th century (Cuvier, 1798). Compared to other mammals, the sum of their unique characteristics has led them to be considered by some previous workers, the most unusual mammals (Vizcaíno \& Loughry, 2008; for a summary see Superina \& Loughry, 2015). They represent the only known mammals with a carapace formed by a mosaic of osteoderms (fixed and mobile) covering the head, body, and tail (Vizcaíno \& Loughry, 2008). Cingulates include extant and extinct armadillos, among them the four extant subfamilies Dasypodinae, Euphractinae, Tolypeutinae, and Chlamyphorinae, as well as the extinct glyptodonts, a group of herbivorous and large-bodied mammals appearing in the late Eocene and disappearing at the beginning of the Holocene (Delsuc et al., 2016; see also Gaudin \& Lyon, 2017 for an alternative classification). The phylogenetic position of glyptodonts within Cingulata is particularly difficult to resolve based on morphological data because of their highly specialized anatomy and the large morphological gap separating them from extant armadillos (Burmeister, 1874; Carlini \& Zurita, 2010; Fariña et al., 2013). This difficulty was recently emphasized by ancient DNA studies showing that phylogenetic analyses of their mitogenomes support a position for glyptodonts at odds with that proposed in prior morphological studies (Billet et al., 2011; Delsuc et al., 2016; Engelmann, 1985; Gaudin \& Wible, 2006; Herrera et al., 2017; Mitchell et al., 2016).

While it has long been accepted that glyptodonts were closely related to extant armadillos (Huxley, 1864), their exact relationships with the latter were never clearly resolved on the basis of morphological data. Flower (1882) initially proposed that glyptodonts were the ancestors of extant armadillos but Ameghino (1884, 1889) disputed this hypothesis, arguing that their great dental and postcranial complexity, as described by Owen (1839), was evidence of their derived nature. The nested position of glyptodonts among extant armadillos has been supported by many authors since then, including by recent phylogenetic analyses using morphological data (Billet et al., 2011; Castellanos, 1932, 1959; Fernicola, 2008; Gaudin \& Wible, 2006; Herrera et al., 2017; Hoffstetter, 1958; Patterson \& Pascual, 1972). However, the consensus stops here. Engelmann (1985) proposed a close relationship of glyptodonts with the extinct Eutatini (Proeutatus and Eutatus) and pampatheres, whereas the analysis of Gaudin and Wible (2006) retrieved glyptodonts in an apical position nested within a large clade gathering euphractines, chlamyphorines, the extinct pampatheres, and some extinct eutatines. A similar hypothesis was also supported by other studies, but with much variations in the composition of this large apical clade (Billet et al., 2011; Fernicola, 2008; Fernicola et al., 2017; Herrera et al., 2017; Porpino et al., 2010). Most of these studies, however, unvaryingly proposed a close relationship between the extinct giant pampatheres and the glyptodonts, in agreement with Patterson and Pascual (1972). Thanks to the progress made in ancient DNA studies and the recent extinction of glyptodonts-at the beginning of the
Holocene (Messineo \& Politis, 2009)-the complete mitochondrial genome of the Pleistocene glyptodont Doedicurus (Burmeister, 1874) was successfully assembled, which gave rise to a completely new phylogenetic hypothesis (Delsuc et al., 2016; Mitchell et al., 2016). Based on analyses of their mitogenomes, glyptodonts were nested within extant armadillos and represented the sister group of a clade formed by chlamyphorines and tolypeutines (Delsuc et al., 2016; Mitchell et al., 2016). Although analyses of morphological matrices using a molecular backbone constraint can detect morphological characters congruent with the molecular pattern (Mitchell et al., 2016), the high level of disagreement between the two data partitions may call into question the phylogenetic signal provided by morphological matrices on cingulates.

External cranial and postcranial skeletal anatomy are already well known for many groups within Cingulata, but the internal cranial anatomy remains understudied. However, its study has already provided data of systematic interest for both the extant and extinct xenarthran diversity (Billet et al., 2015; Billet et al., 2017; Boscaini et al., 2020; Boscaini et al., 2018; Fernicola et al., 2012; Tambusso \& Fariña, 2015a; Tambusso \& Fariña, 2015b; Tambusso et al., 2021; Zurita et al., 2011). Intracranial osseous canals provide important pathways for innervation and vascularization of the head (Evans \& de Lahunta, 2012). The diversity and phylogenetic signal of their intracranial trajectories are poorly known, as these hidden structures are rarely described in mammals, in general, including xenarthrans (e.g., Wible \& Gaudin, 2004). In contrast, their external openings on the cranium are often described and scored in phylogenetic matrices (e.g., 37/131 of cranial characters-Gaudin \& Wible, 2006).

Here we present a comparative investigation of intracranial osseous canals and cavities in a diverse sample of extant and extinct cingulates, including the earliest well-preserved glyptodont crania, using X-ray microtomography. The 3D virtual reconstruction of selected canals and cavities related to cranial vascularization, innervation, or upper tooth insertion enabled us to compare the locations, trajectories, and shape of each homologous structure and discuss their potential interest for cingulate systematics. We tentatively reconstructed the evolutionary history of these traits using a molecularly constrained phylogeny, and we discuss the potential effects of development and allometry on their variation. These comparisons allowed us to propose new potential characters that may be used to further explore the origins of glyptodonts within cingulates on a morphological basis.

\section{2 | MATERIALS AND METHODS}

\section{1 | Sampling}

We examined the crania of 33 extant and extinct xenarthran specimens. Two specimens belonging to the Pilosa (sloths and anteaters) were chosen as outgroups. The remaining 31 crania belonged to Cingulata (Table 1). This sample included specimens representing the nine extant genera as well as three small developmental series 


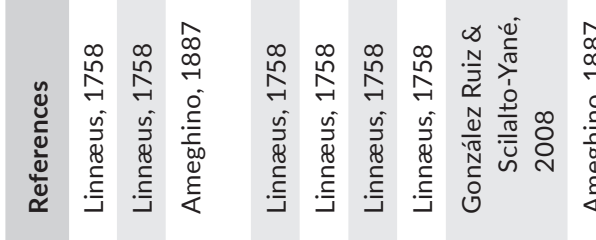

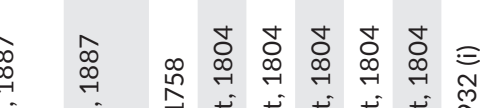

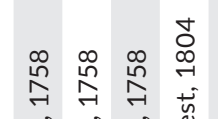

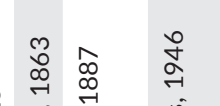

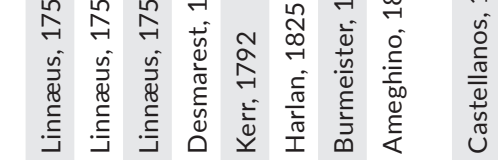

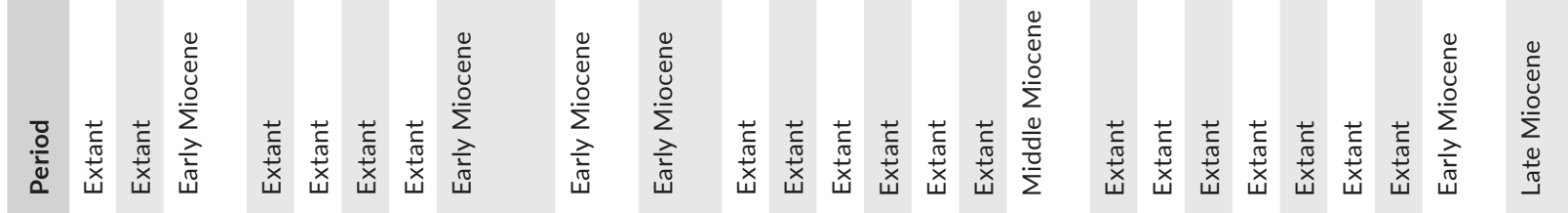

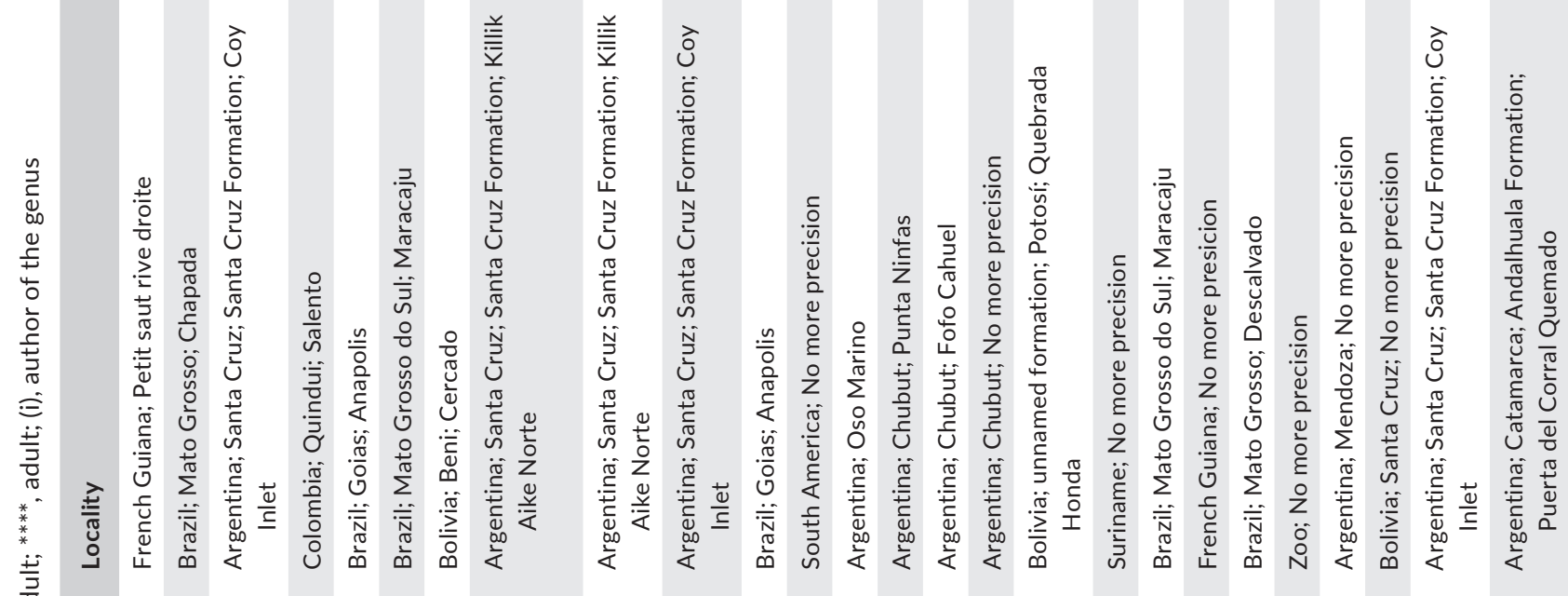

吾

*.

产

* है है

* ब.

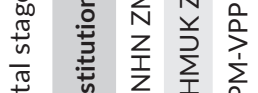

요 공

ले

焉

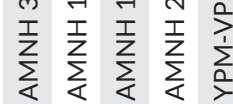

ฆ

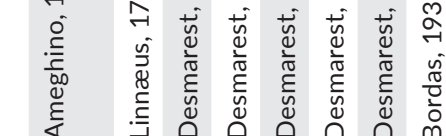

ֻัญ

$\frac{\ddot{s}}{4}$

के

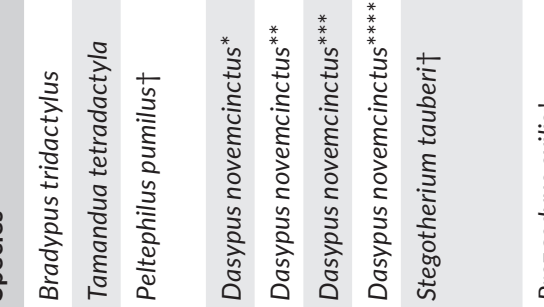

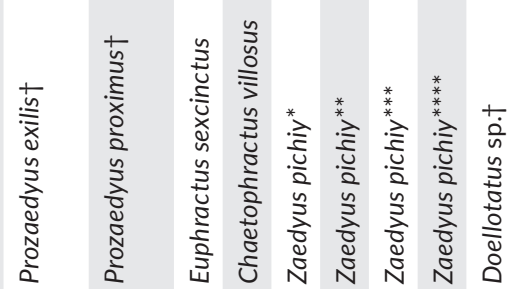

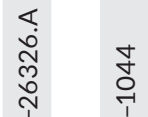

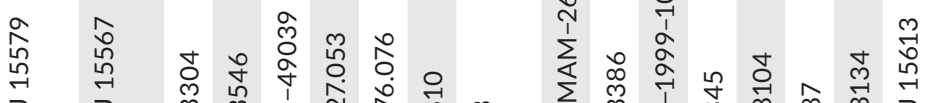

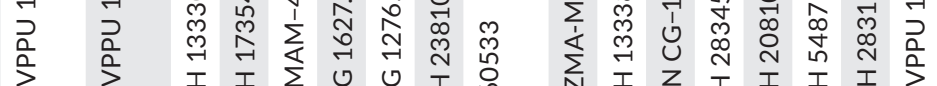

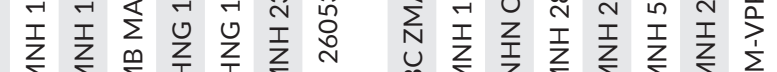

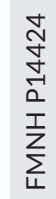

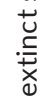

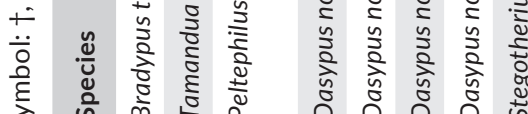

जे की के व व व 0 क

离

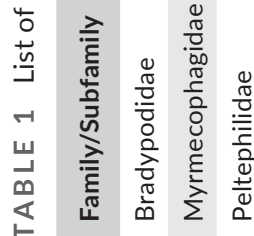

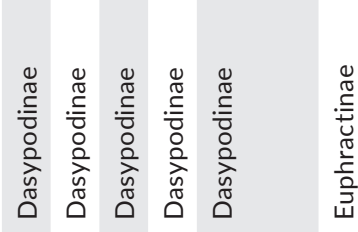

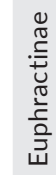
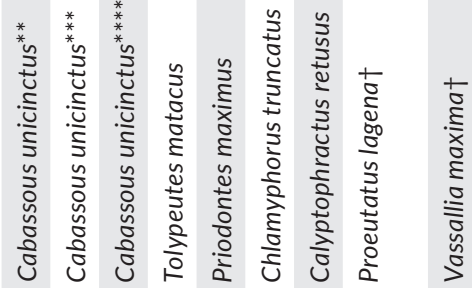

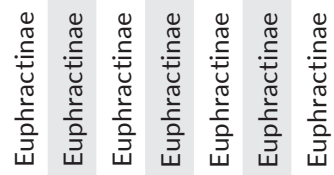

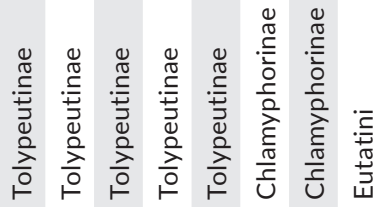

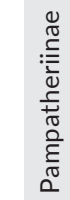


in phylogenetically distant species (Dasypus novemcinctus, Zaedyus pichiy, Cabassous unicinctus), with the aim of better understanding the ontogenetic variation of the selected anatomical structures. For the determination of relative ages within the developmental series of Dasypus, we used the protocol of Le Verger et al., (2020) to analyze the relationship among size, ossification, and dental eruption. Because members of the genus Cabassous and Zaedyus only have one dental generation (the possession of two dental generations seems to be restricted to Dasypus-Ciancio et al., 2012), dental eruption could not be used to determine ontogenetic stage. For these taxa, we used only the relationship between degree of ossification and size. The cingulate specimens also included 14 specimens belonging to fossil species, among them six glyptodonts (Table 1). This sample covered more than 18 million years of cingulate evolutionary history and includes all the major cingulate subfamilies. Our sample does not allow us to evaluate intraspecific variation in all taxa. However, we were able to estimate this variation in three species for which we possess developmental series. For each of them, we analyzed scans of four additional adult specimens. The adult intraspecific sampling is available in Table S1. Species identification was based on collection data, geographical origin, cranial anatomy, and the literature on cingulate taxonomy (e.g., Abba et al., 2015; Carlini et al., 2016; Gaudin \& Lyon, 2017; Gaudin \& Wible, 2006; Hayssen, 2014; McBee \& Baker, 1982; Scott, 1903; Smith \& Owen, 2017; Wetzel, 1985; Wetzel et al., 2007). Digital data for all specimens were acquired using $X$-ray micro-computed tomography $(\mu \mathrm{CT})$. Specimens were scanned on X-ray tomography imagery platforms at the American Museum of Natural History (New York, USA); the Museum national d'Histoire naturelle (France) in Paris (AST-RX platform), the University of Montpellier (France-MRI platform), and the Museum für Naturkunde (ZMB) in Berlin (Phoenix nanotom [General Electric GmbH Wunstorf, Germany]). Three-dimensional reconstructions of the selected structures were performed using stacks of digital $\mu \mathrm{CT}$ images with MIMICS v. 21.0 software (3D Medical Image Processing Software, Materialize, Leuven, Belgium). The visualization of 3D models was also conducted with AVIZO v. 9.7.0 software (Visualization Sciences Group, Burlington, MA, USA). A large part of specimens scanned will be available on MorphoMuseum for 3D models and on MorphoSource for scans. Specimens scanned by LGR will be available upon request to LGR. The list of specimens is given in Table S2.

\section{2 | Selected regions of interest and anatomical nomenclature}

We selected several osseous anatomical complexes in the internal cranial anatomy of cingulates that are poorly known and of interest for this study, such as dental alveoli and several specific intraosseous canals. The latter mostly correspond to vascular pathways and/or the courses of cranial nerves involved in the innervation of various cranial areas: the nasolacrimal canal, the palatine canal, the sphenopalatine canal, the canal for the frontal diploic vein, the transverse 
canal, the orbitotemporal canal, the canal for the capsuloparietal emissary vein, and the posttemporal canal.

Our study is focused only on the cranium and does not include the mandible. Therefore, we are only interested in upper dentition. Except for Dasypus, which represents a special case (see Ciancio et al., 2012), the homologies in the dental row among the different species of Cingulata are not known mainly because of the drastic reduction in dental complexity (Vizcaíno, 2009). For glyptodonts, previous studies conventionally designated the whole set of teeth as molariform but without further precision (e.g., González Ruiz et al., 2015). We, therefore, chose to treat all teeth as molariform (= Mf; see Herrera et al., 2017 for a different nomenclature and Table S3 for the dental formula of each specimen of our study with greater precision).

Only those intracranial canals whose sampled variation appeared to bear clear systematic information were selected in this work (Figure 1). Nonselected canals generally showed asymmetric and intraspecific variation according to our intraspecific sample (Table S1-e.g., hypoglossal canal; trajectory of the internal carotid artery-see also Patterson et al., 1989; Gaudin, 1995) or provided no new data (e.g., infraorbital canal) with respect to what was already described or scored for the systematics of the group (Gaudin \& Lyon, 2017; Gaudin \& Wible, 2006; Wible \& Gaudin, 2004). Other nonselected canals were rarely visible in all specimens (often due to taphonomynot in place and/or obscured by a hard and dense matrix) and were therefore difficult to compare. Specimens that presented a canal that was too incomplete are not described in the relevant section. For the identification and nomenclature of the selected intracranial canals, our study used previous work describing intracranial anatomy in cingulates and eutherians in general (Evans \& de Lahunta, 2012; Gaudin, 2004; Gaudin \& Lyon, 2017; Muizon et al., 2015; Thewissen, 1989; Wible, 1993; Wible \& Gaudin, 2004). We have indicated for each selected region of interest: the variation of these regions during ontogeny, a synthetic comparison among specimens, and the formalization of potential discrete or continuous characters to highlight potential evolutionary scenarios to be mapped onto the tree of cingulates. The formalization of new characters was performed based on observations that were stable among glyptodonts and were shared with

(A))

$$
\text { orbitotemporal groove }
$$

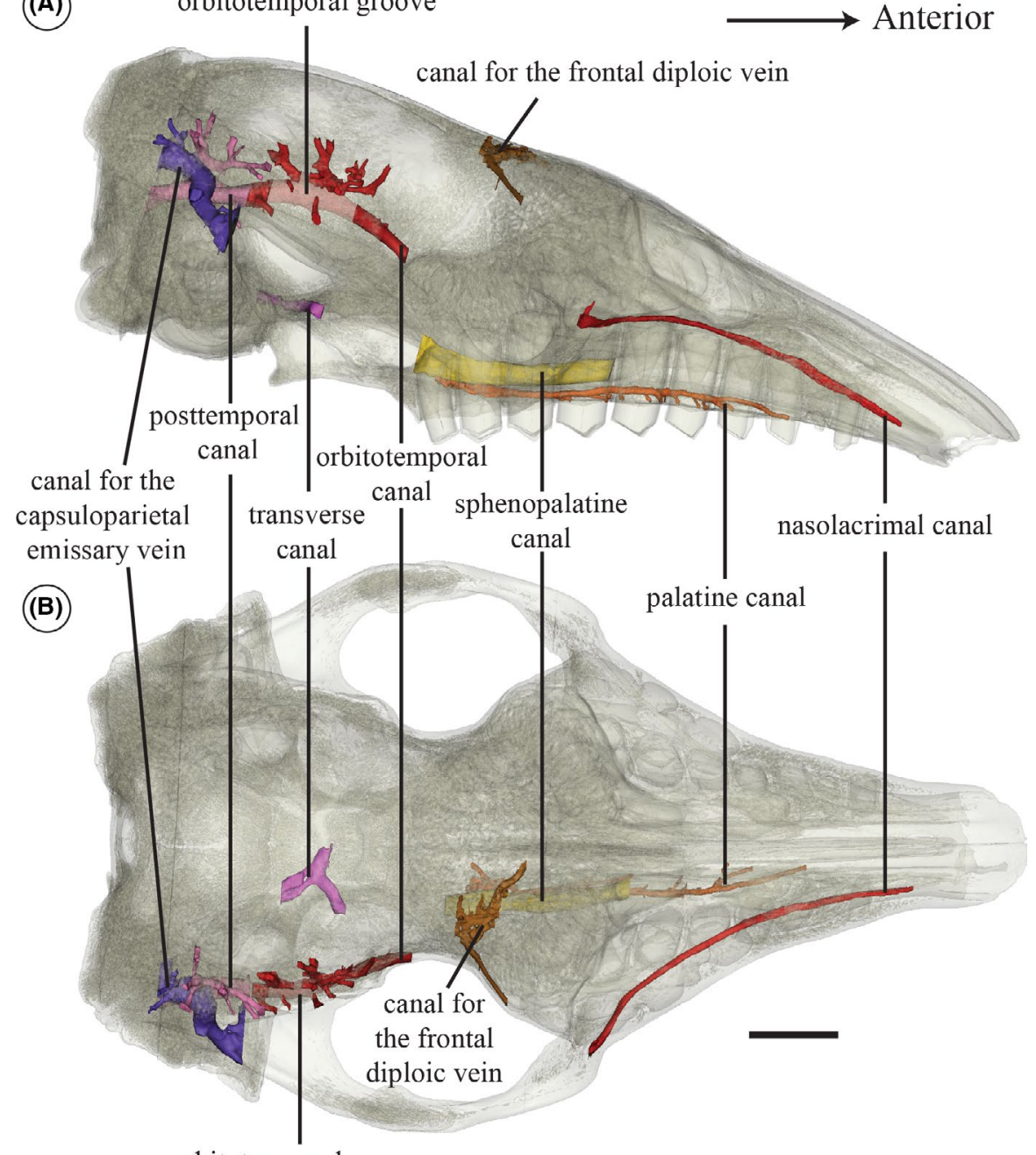

orbitotemporal groove

FIGURE 1 Illustration of the selected internal canals on the transparent cranium of Euphractus sexcinctus AMNH 133304 in right lateral (A) and ventral (B) views. Scale $=1 \mathrm{~cm}$ 
some nonglyptodont cingulates, so that they could provide pertinent information when investigating glyptodont origins.

\subsection{Virtual reconstruction of the selected regions}

When present, the most dorsal part of the teeth did not always fill the whole alveolar cavity, leaving a void between the roof of the alveolar cavity and the dorsal edge of the tooth. Because we selected the internal orientation and curvature of the whole dental row for study, the reconstruction of alveoli was preferred over the modeling of teeth, which were sometimes absent for our specimens. In some cases, the distinction between the limit of the alveolar wall, the tooth, and the sediment was not identifiable. In this case, we modeled only the distinguishable structures to allow comparison (e.g., Doellotatus in Figure 2).

Within the cranium, a canal corresponds to a duct completely enclosed in one or more bones and which usually provides a passageway to vessels and/or nerves. In some cases, a canal may not be continuously enclosed by bone, and thus turns into a groove for part of its course (e.g., the orbitotemporal canal). In such a case, we have reconstructed the course of the groove in a manner similar to that of a canal, but we illustrated the areas corresponding to the groove with increased transparency. In some cases, two canals were confluent in such a way that it was no longer possible to distinguish which part of the duct corresponds to the passage of which vessel or nerve. These regions of confluence were specified in each of our reconstructions by a shaded area (e.g., the posttemporal canal and canal for the capsuloparietal emissary vein). Most selected canals were continuous with external or internal foramina. Figure S1 shows the location of each of these foramina in Euphractus.

\section{$2.4 \mid$ Measurements}

A few specific measurements were taken for comparison where quantification seemed to offer a better account of the observed variation than a qualitative description. Cranium length, height, and width were measured to calculate the geometric mean of each specimen (= geometric mean, an estimator of the size of a specimen defined by the cubic root of the product of the three variables, Claude, 2008). The geometric mean was log-transformed to facilitate graphing of the data (Claude, 2008). Several other cranial measurements were selected, and their variation was compared to that of the geometric mean in our sample (Table S4 and Figure S2). These measurements were selected in order to quantify the following aspects that appeared interesting to us after our anatomical observations: (a) the relative height of the dental row (i.e., GDRH/GCH =the ratio between the greatest dental row height and the greatest cranium height); (b) the angle between the straight line marked by the ventral most point of the tentorial process and the dorsal most point of the annular ridge (see Wible \& Spaulding, 2013) and the horizontal anteroposterior axis, defined here by the straight line between the mesial edge of the first tooth and the distal edge of the last tooth in sagittal view. This allowed for a comparison of the internal vault inclination (IVI angle) among taxa. These measurements are further explained and summarized in Figure S2; they were taken using the linear distance and angle tools of MIMICS v. 21.0 software.

\subsection{Reconstructing evolutionary scenarios for intracranial traits}

In order to visualize possible evolutionary scenarios for the discrete and continuous intracranial traits defined based on our observations, we reconstructed a cladogram that focused on the taxa in our sample by performing a parsimony analysis using PAUP v. 4.0a167 (Swofford, 2002). We used the morphological matrix of Billet et al., (2011) (largely based on that of Gaudin \& Wible, 2006), which we limited to the genera in our sample. The initial matrix included all the genera of our sample except for one extant genus (Calyptophractus), along with four fossil genera of glyptodonts: "Cochlops," Eucinepeltus, "Metopotoxus," and Glyptodon. We have retained the quotation marks for the genera "Cochlops" and "Metopotoxus" in agreement with the notes of Scott (1903). They have otherwise not been revised since Scott's (1903) report. We scored these taxa (i.e., Calyptophractus and several glyptodonts) based on our CT-scanned specimens and added them to the analysis. After this stage, the matrix included 22 taxa scored for 125 characters (Data S1). We performed the same analysis as Billet et al., (2011), with a heuristic search involving 1000 random addition replicates, with 27 morphological characters treated as ordered and treating taxa with multiple states as polymorphic (Data S1). Following the recent molecular works of Delsuc et al., (2016) and Mitchell et al., (2016), we enforced a backbone constraint similar to that of Mitchell et al., (2016). Because this resulted in an unusual position for Proeutatus (i.e., as the sister group of euphractines), contrary to its usual placement close to the glyptodonts in morphological analyses (Billet et al., 2011; Engelmann, 1985; Gaudin \& Wible, 2006; Herrera et al., 2017), we added a constraint on this taxon to assign it a priori to a position close to glyptodonts (Figure S3A). This choice, therefore, leads us to consider Eutatini as excluded from euphractines.

By using this approach, our aim was only to obtain a more consensual topology, based on recent morphological and molecular analyses, in order to discuss the relevance of our characters. This study is thus not intended to produce a new phylogenetic analysis. The strict consensus of the most parsimonious trees (with two polytomies-extant

FIGURE 2 Diversity of the dental alveolar cavities in our cingulate sample in lateral (red square), ventral (yellow square) and anterior (green square) view. Crania are reconstructed with transparency to leave the cavities apparent. Colors of species names refer to their attribution at the subfamilial level according to molecular analyses (lower right panel); extinct species not allocated to one of these subfamilies are shown in black. $†$ represents an extinct taxon. Scale $=1$ operator \# cm 


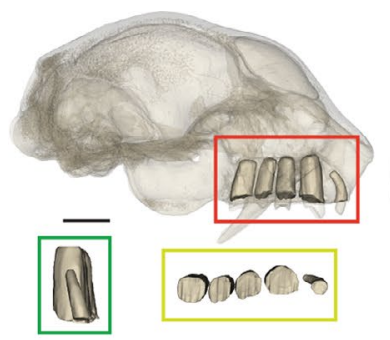

Bradypus tridactylus

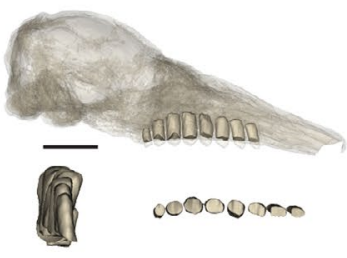

Prozaedyus proximus $\uparrow$

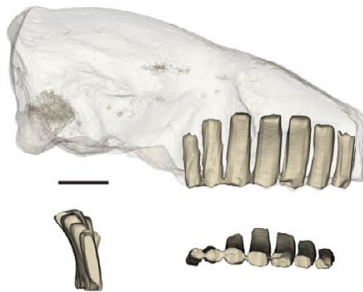

Doellotatus sp. $\uparrow$

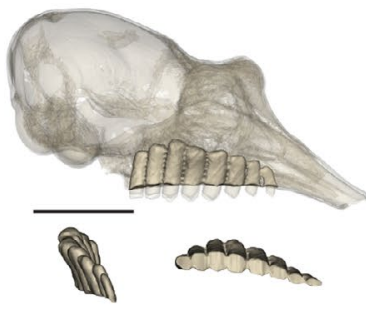

Chlamyphorus truncatus

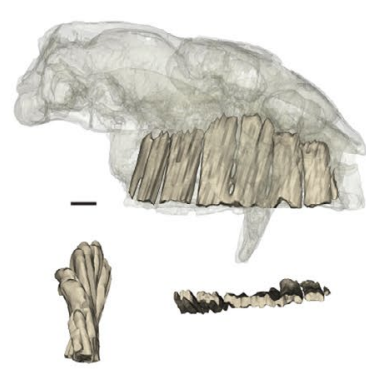

«Metopotoxus » anceps $\dagger$

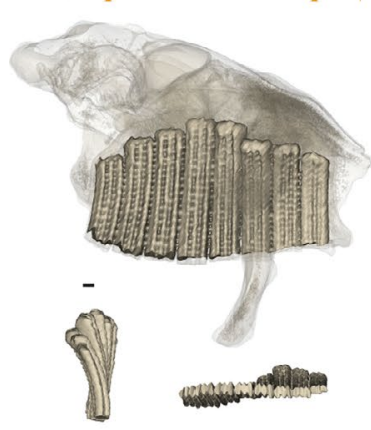

Glyptodon sp。广

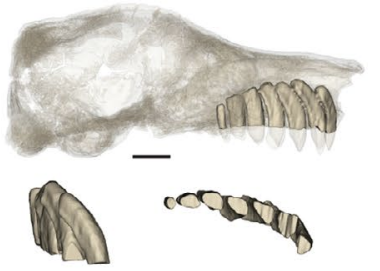

Peltephilus pumilus $\uparrow$

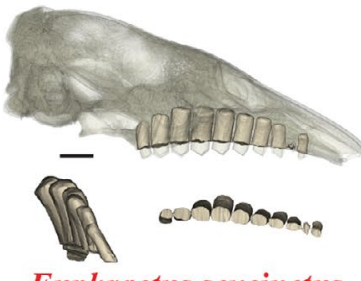

Euphractus sexcinctus

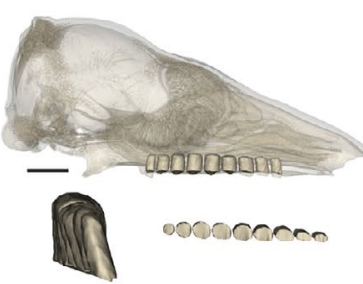

Cabassous unicinctus *

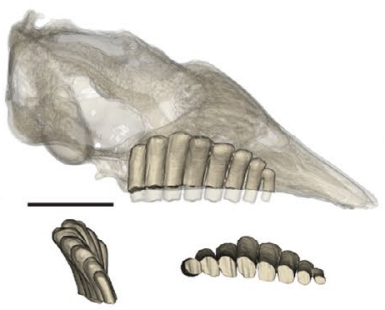

Calyptophractus retusus

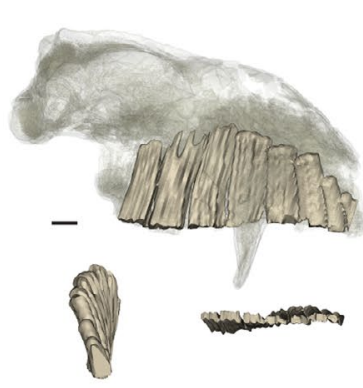

Propalachoplophorus minus †*
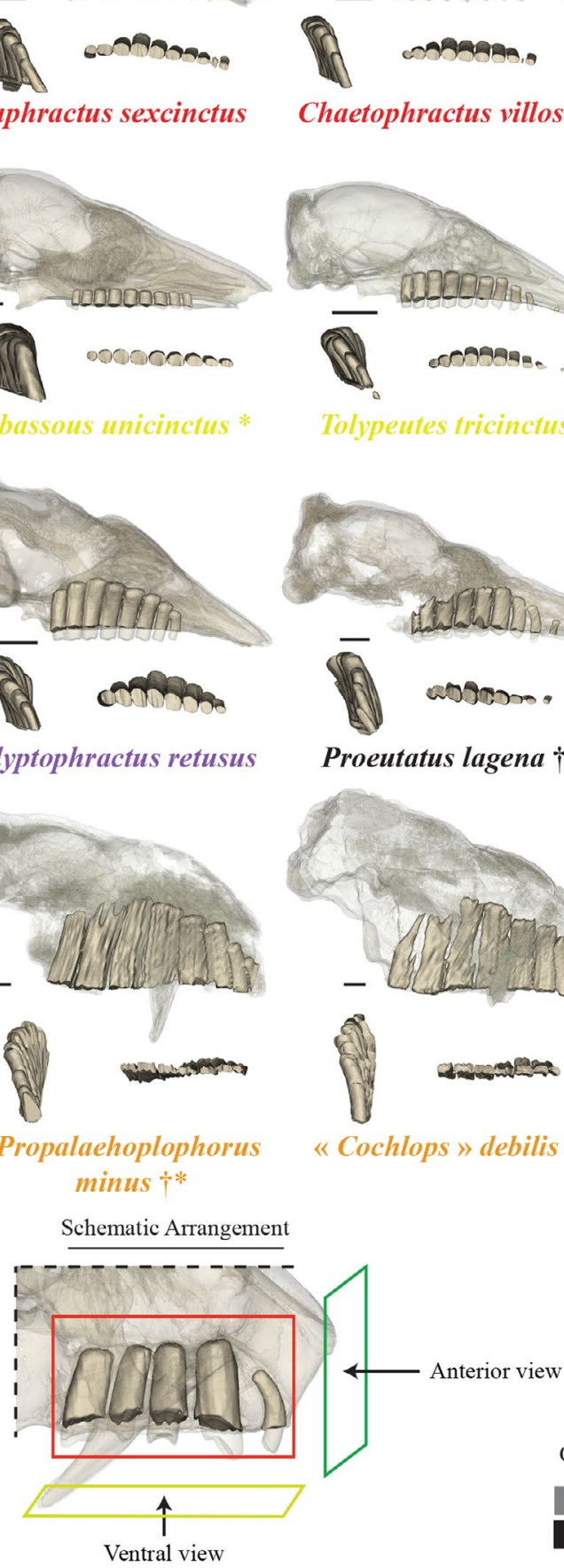

Tolypeutes tricinctus

Proeutatus lagena $\dagger$

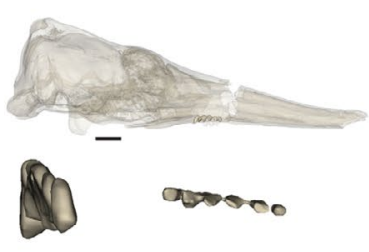

Stegotherium tauberi $\uparrow$

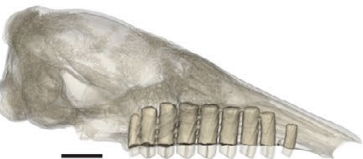

Chaetophractus villosus
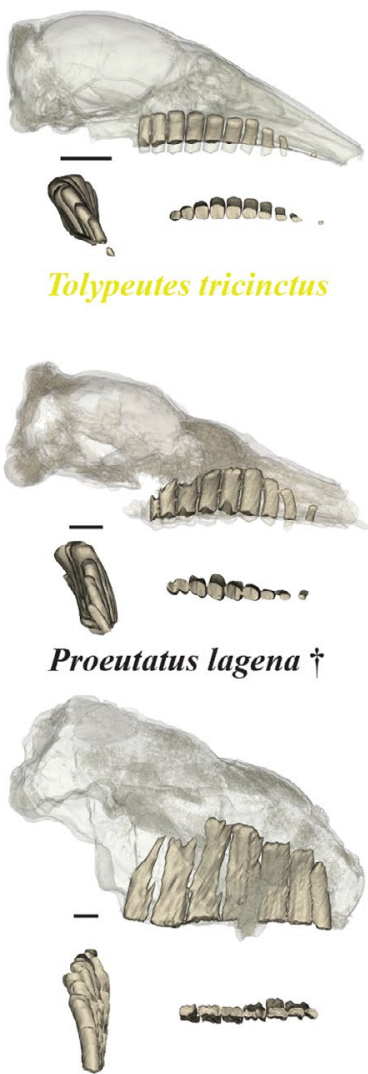

«Cochlops » debilis $\uparrow \quad$ Eucinepeltus complicatus $\uparrow$

Phylogenetic relationships:

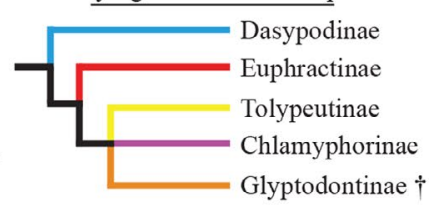

Other specimens: Orientation:

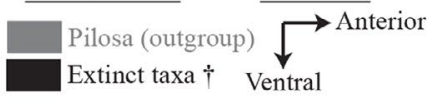


euphractines and glyptodonts except for "Metopotoxus") obtained was then used to calculate branch lengths in order to explore evolutionary scenarios for our qualitative and quantitative observations over the entire topology of the tree. The strict consensus was used as a baseline cladogram (Figure S3B-the strict consensus of the same analysis without constraint is illustrated in Figure S3C for comparison). As the optimization options of the analysis can affect the length of the branches, we have chosen to favor the hypothesis of convergence (= DELTRAN) rather than reversion because they have been regarded as more likely (Wake et al., 2011). For the reconstruction of evolutionary scenarios for intracranial discrete or continuous traits, one needs to complete missing data and resolve polytomies. For the latter, we used the multi2di function of the ape package of R (Paradis \& Schliep, 2019). The function resolves polytomies by adding one or several additional node(s) and corresponding branch(es) of length 0 . The duplicate nodes thus have the same values, allowing the removal of duplicates a posteriori. In order to facilitate the visualization of the evolutionary scenarios on the tree, we have rendered the tree ultrametric using force.ultrametric function of the phytools package of $R$ (Revell, 2012). For the discrete traits, the missing data (i.e., 1 taxon for characters 1 and 2 [not applicable], 7 taxa for character 4; 1 taxon for character 5-see Results) were completed according to their ancestral node optimization. In case of optimization uncertainties, we also favored convergences for the same reason mentioned previously. The reconstruction and mapping of ancestral states were performed using stochastic mapping with a symmetric condition matrix (i.e., one for which all transformation rates are considered equivalent; see Bollback, 2006; Revell, 2012). This analysis was performed using the make.simmap function of the phytools package of $\mathrm{R}$, with which we produced 100 simulations for each character. For continuous traits, missing data (i.e., 2 taxa for the character 8) were estimated using an approach combining the use of multiple imputations with procrustean superimposition of principal component analysis results performed on all measurements (Table S4; Clavel et al., 2014) with the estim function of the mVMORPH package of $\mathrm{R}$ (Clavel et al., 2015). Then, the reconstruction of the ancestral states was performed using maximum likelihood with the contMap function of the phytools package of R (Revell, 2012).

\section{6 | Institutional Abbreviations}

AMNH, American Museum of Natural History, New York, USA; FMNH, Field Museum of Natural History, Chicago, USA; MHNG, Muséum d'Histoire Naturelle de Genève, Genève, Switzerland; MNHN, Muséum National d'Histoire Naturelle, Zoologie et Anatomie comparée collections (ZM), Mammifères et Oiseaux collections (MO), fossil mammal collections, Pampean (F.PAM), Paris, France; NBC, Naturalis Biodiversity Center, Leiden, Holland NHMUK, Natural History Museum, London; NMNH, National Museum of Natural History, Smithsonian Institution, Washington, DC, USA; UF, University of Florida, Gainesville, USA; YPM-VPPU, Princeton University collection housed at Peabody Museum, Yale University, USA; ZMB, Museum für Naturkunde, Berlin, Germany.

\section{3 | RESULTS: ANATOMICAL DESCRIPTION AND COMPARISON}

\section{1 | Teeth and alveolar cavities: Orientation, curvature, and height}

The three species sampled intraspecifically (Dasypus novemcinctus, Zaedyus pichiy, and Cabassous unicinctus-Table 1) do not show any ontogenetic variation in the orientation and curvature of the teeth compared with the pattern observed in adults (see below). In Dasypus and Zaedyus, the relative height of teeth shows an increase from the youngest to the oldest specimens, suggesting an increase in height during ontogeny (Figure 3). In Cabassous, which possess a reduced dentition as Dasypus, no clear ontogenetic trend has been observed, but we lack a stage as young as those present in Dasypus and Zaedyus (Figure 3).

Height: The relative height of the alveolar cavities distinguishes specimens with reduced teeth, such as Stegotherium, Dasypus, Cabassous, and Priodontes, from other cingulate species, some of which may even show extremely enlarged teeth, as is the case in glyptodonts (Figure 2, Table S4).

In taxa with reduced teeth (unfunctional supernumerary teeth are not considered; see González Ruiz et al., 2014, 2015, 2017; González Ruiz \& MacPhee, 2014), the height of the alveolar cavity in lateral view is practically the same for all teeth (Figure 2). In the other taxa, the dorsal profile of the dental row in lateral view is curved (dorsally convex): that is, teeth gradually increase in height backward until the middle of the dental series and then gradually decrease in height posteriorly. The most dorsal point is reached in the middle of the dental row (at the level of Mf5 in dental rows containing 7-10 Mf) in Euphractus (at Mf5/Mf9), Chaetophractus (at Mf5/Mf9), Doellotatus (at Mf5/Mf9-10) and Tolypeutes (at 5Mf/Mf9), and more anteriorly in Peltephilus (at Mf2/Mf7), and Proeutatus (at 4Mf/Mf9). In Bradypus, this dorsal point is attained more anteriorly (at Mf2/Mf5). It is reached more posteriorly in Zaedyus (at Mf5/Mf8), Prozaedyus (at Mf5/Mf8 and Mf6/Mf9), chlamyphorines (at Mf6/Mf8), and most glyptodonts (at Mf5-6/Mf8). In addition, the GDRH/GCH ratio, which expresses dental height relative to cranium height, seems to be correlated with body size $\left(R^{2}=0.5363 ; P\right.$-value $\left.=9.42 \mathrm{E}-06\right)$, showing that large-sized taxa have relatively taller dentitions. This is reminiscent of the increase in height of the dental row during ontogeny in Dasypus and Zaedyus. Most large-bodied taxa in the sample, that is, Vassallia and glyptodonts, but not Priodontes, do indeed show a strongly elevated dentition in relation to cranium depth (Figure 4). This is also the case in Peltephilus for which the height of the cranium is particularly low in relation to its length. Although they are small (i.e., $\mathrm{GCL}<43 \mathrm{~mm}$ ), chlamyphorines show a tooth height comparable in proportion to the larger-sized Euphractus, Chaetophractus, and Proeutatus (Figure 4), meaning that they depart slightly from the detected allometric trend in having teeth taller than expected for their size. Relative tooth height is lower in Prozaedyus, Zaedyus, Tolypeutes, and Cabassous and extremely low in specimens with dental reduction-Stegotherium, Dasypus, and Priodontes (Figure 4). 
Journal of Anatomy

Zaedyus pichiy

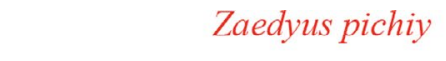

\section{Dasypus novemcinctus}
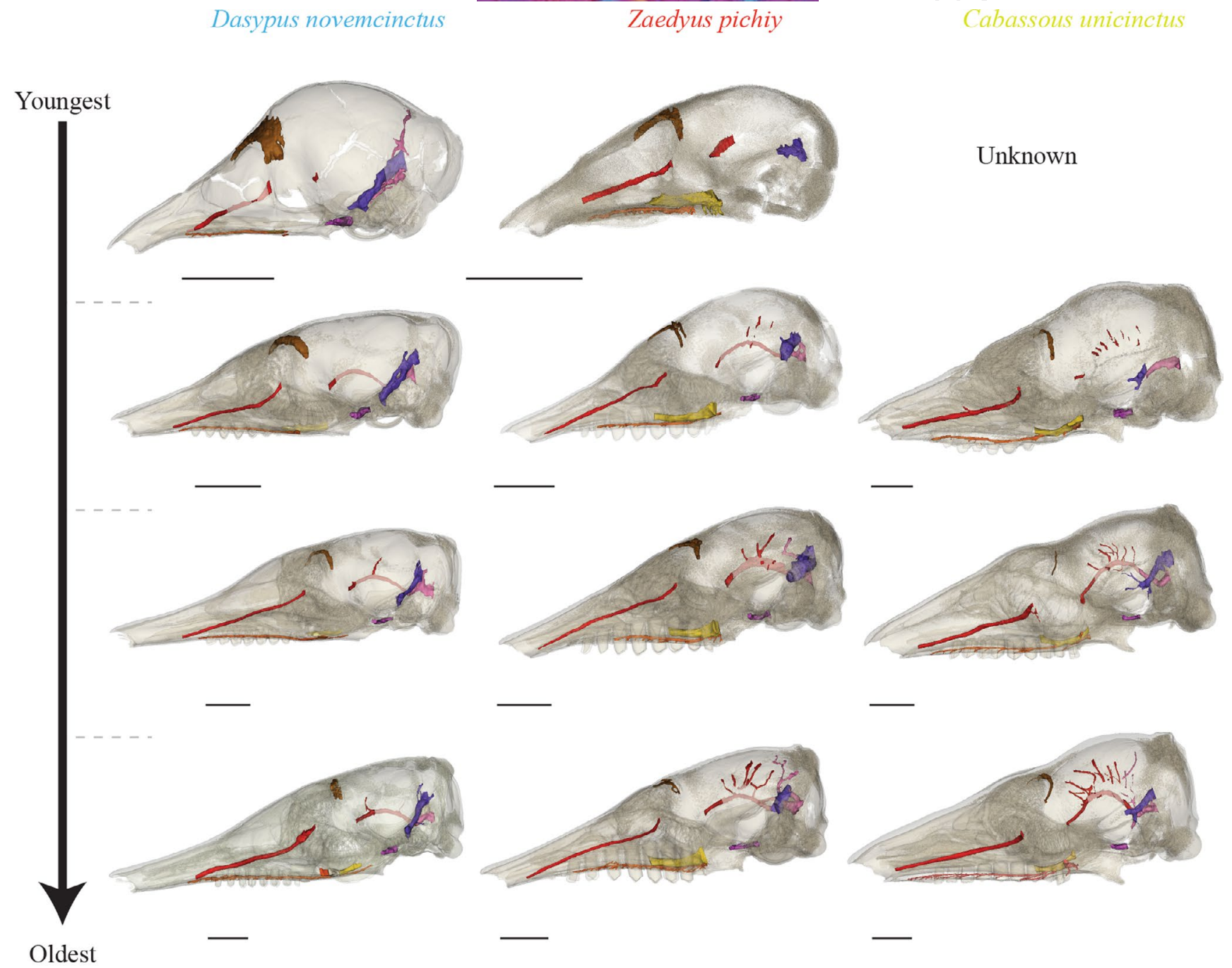

(adult stage)

FIGURE 3 Ontogenetic variation of internal canals selected in this study viewed in lateral view on transparent crania in each developmental series (Dasypus, Zaedyus and Cabassous). Note that early postnatal stages for Cabassous are not documented in our sample. See Le Verger et al., (2020) for the determination of stages. Phylogenetic relationships are indicated with colors following Figure S3. The color of canals follows that of Figure 1 . Scale $=1 \mathrm{~cm}$

Curvature and Orientation: As visible in anterior and ventral views (Figure 2), Stegotherium, Priodontes, and Cabassous exhibit a rather homogenous curvature and orientation of teeth along the dental row while most cingulates show gradual changes in these aspects anteroposteriorly. In most cingulates, anterior teeth are tilted lingually, that is, tilted with a medially offset apex, while most posterior teeth often tilt labially (character 5 in Gaudin, 2004). The tilt of posterior teeth is often much less pronounced than for anterior teeth. Similarly, taxa that show curved crowns generally show anterior teeth with an inward curvature (lingual convexity) which can be strongest in the middle of the dental row, while the two posteriormost teeth often show a lesser degree of inward curvature or even an outward curvature (labial convexity). A strong inward curvature of anterior teeth is observed in Peltephilus, Doellotatus, Tolypeutes, Vassallia, chlamyphorines, and glyptodonts in our sample, whereas other taxa show straighter crowns, and an outward curvature is observed in Dasypus. In lateral view, the first tooth (Mf1; P1 for Dasypus) or teeth show a mesial curvature (mesial convexity) and a mesially offset apex in Bradypus, Peltephilus, Proeutatus, Vassallia, Propalaehoplophorus, and Eucinepeltus. Mf1 is also tilted with a mesially offset apex in Prozaedyus. Finally, the two to three posteriormost teeth are distinctly tilted with a distally offset apex in Bradypus and glyptodonts. Most other loci and taxa exhibit a nearly vertical orientation of teeth in lateral view.

Based on these observations, we propose scrutinizing evolutionary scenarios for the following two characters of the dentition (see Table 2).

Character 1 (discrete-unordered): Position of the most dorsal point of the dorsal convexity of the tooth row.

State (0): Toothrow not dorsally convex.

State (1): Anterior to middle of the tooth row.

State (2): At the middle of the tooth row. 


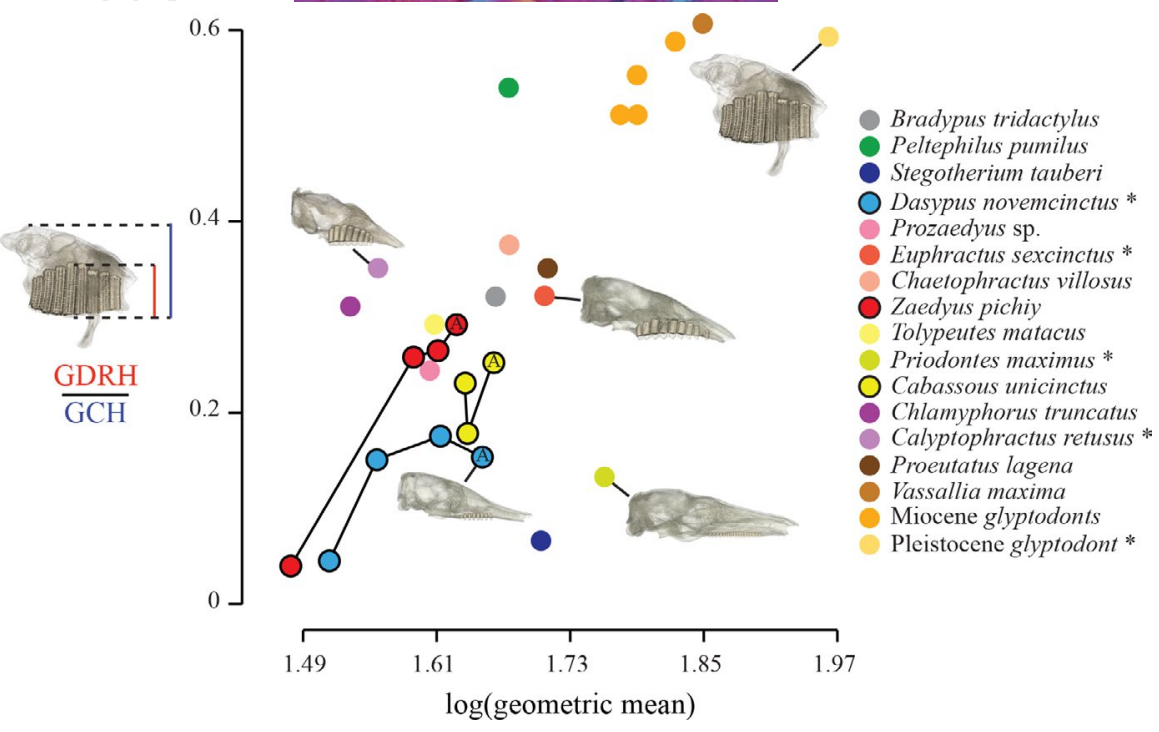

FIGURE 4 Distribution of the ratio of greatest dental row height (GDRH) to greatest cranium height (GCH) with respect to cranial size (= log(geometric mean); see Materials \& Methods). For each of the three developmental series, A, symbolizes the adult specimen. Crania of specimens marked with an asterisk are illustrated in the graph

TAB LE 2 Data matrix with character scores for each genus. Characters 1 and 7 are discrete, and character 8 is continuous (see text). Symbols: -, not applicable; ?, missing data; †, extinct species.

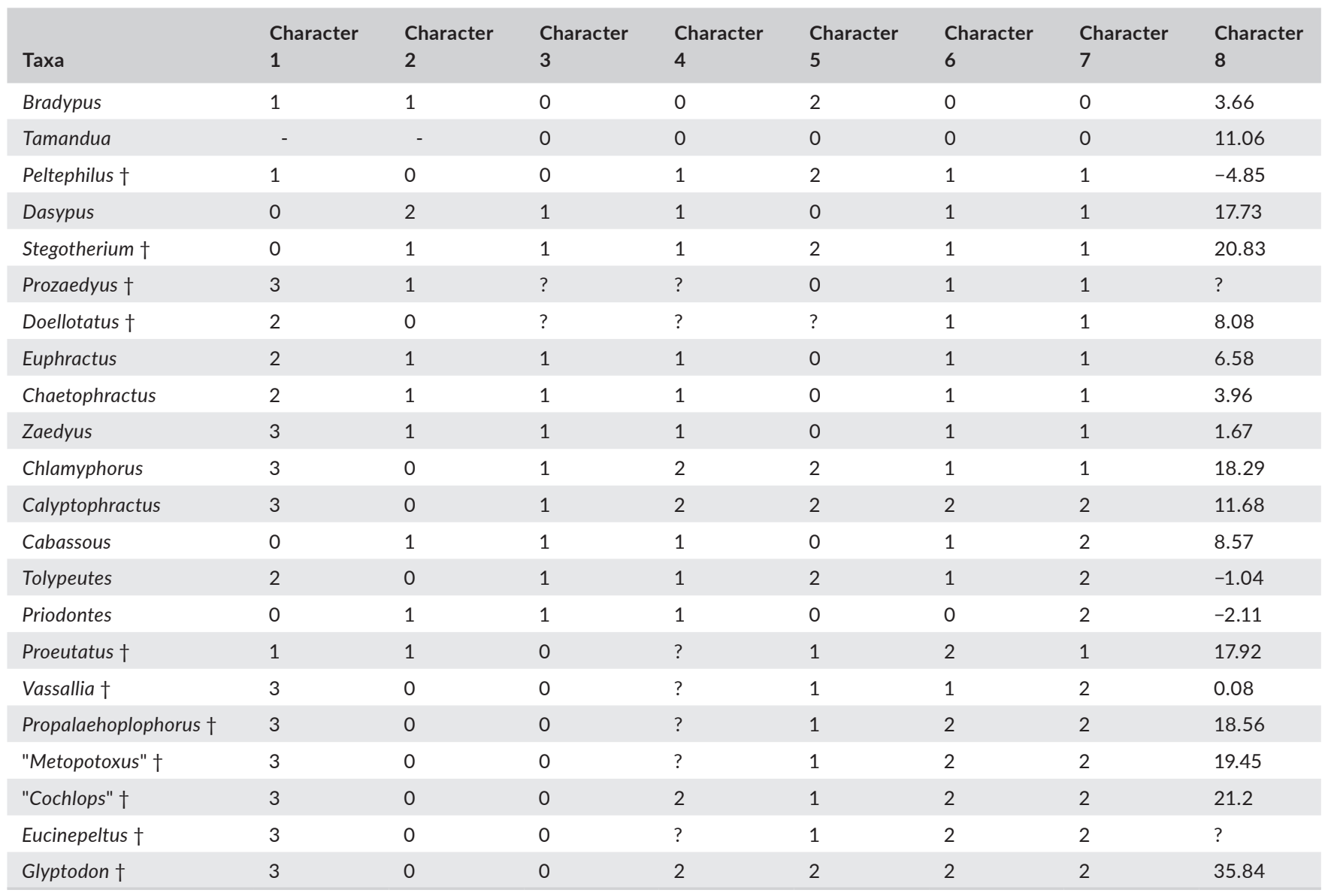

State (3): Posterior to middle of the tooth row.

Character 2 (discrete-unordered): Curvature of anterior teeth in anterior view.
State (0): Inward curvature.

State (1): Straight.

State (2): Outward curvature. 


\section{2 | Cranial Canals}

\subsection{1 | Frontal Diploic Vein canal}

The course of this canal is entirely within the frontal bone. It opens externally at one or exceptionally two foramina located in the orbitotemporal fossa, slightly ventral to the most dorsal part of the orbital margin (Figure S1). Internally, the canal opens through one or more foramina located posterior to the annular ridge and near the midline without ever crossing it (Figure S4). This canal conveys the frontal diploic vein, an emissary of the dorsal cerebral vein/dorsal sagittal sinus, or a vein issuing from the frontal diploë (Evans \& de Lahunta, 2012; Muizon et al., 2015; Thewissen, 1989; Wible \& Gaudin, 2004).

In early ontogeny, the canal of the frontal diploic vein is initially extremely thick in the youngest specimens of Dasypus (see also Billet et al., 2017) and Zaedyus and occupies a large part of the frontal bone (Figures 3 and 5). Its relative diameter is considerably reduced in older specimens of Dasypus and Zaedyus, with no change in its curved trajectory in Zaedyus, but becoming more strictly transverse in the adult stage in Dasypus (Figures 3 and 5). In Cabassous, it remains fairly similar from juvenile to adult stages in our sample (Figures 3 and 5).

\section{Dasypus novemcinctus}

Youngest
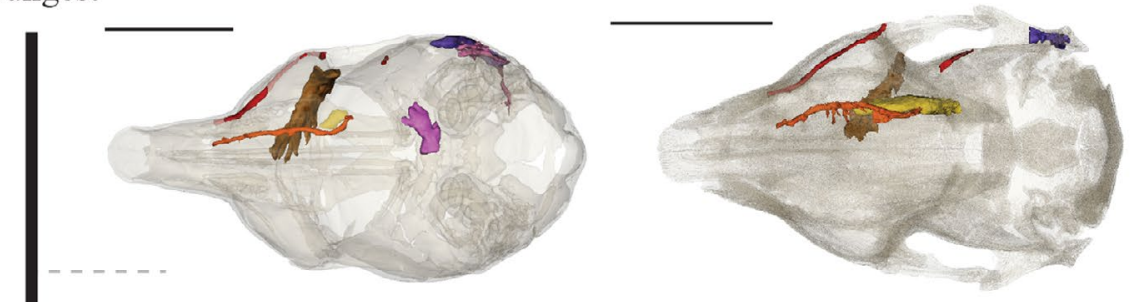

Unknown
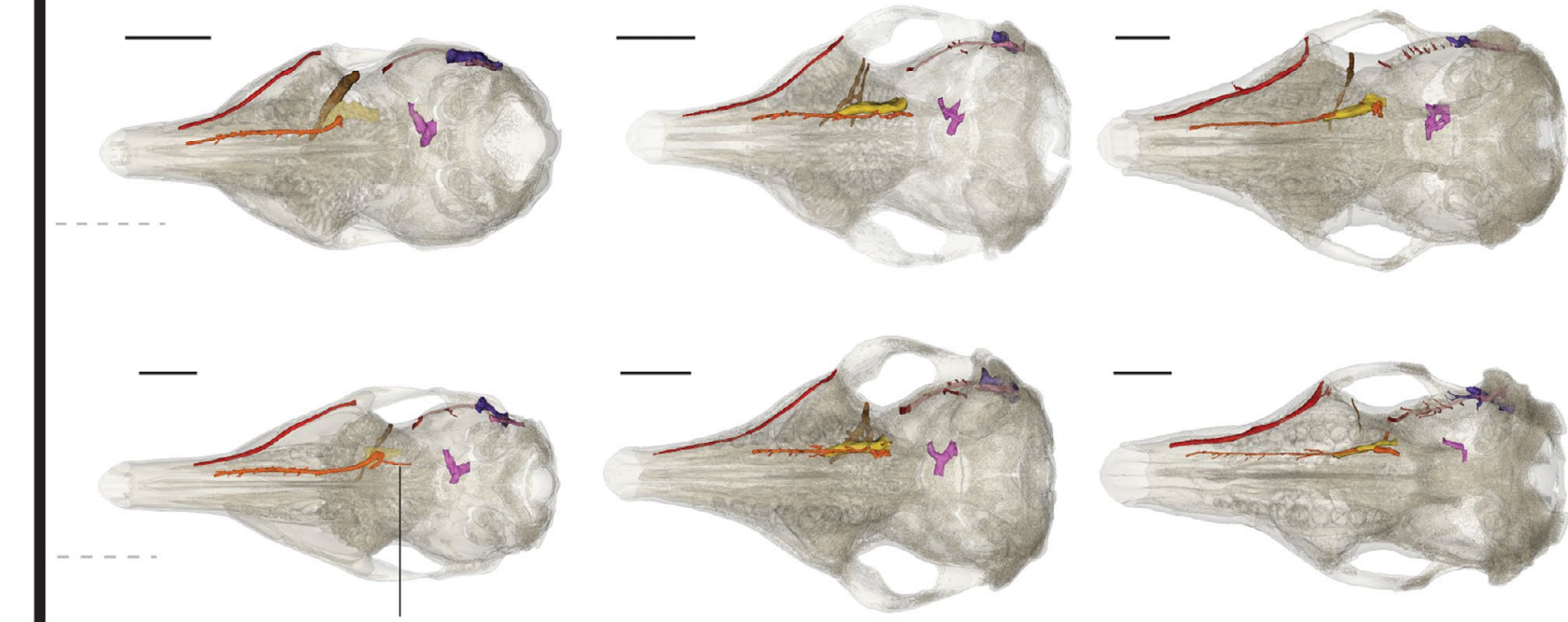

pbplc

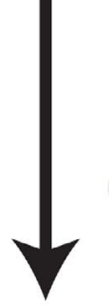

Oldest

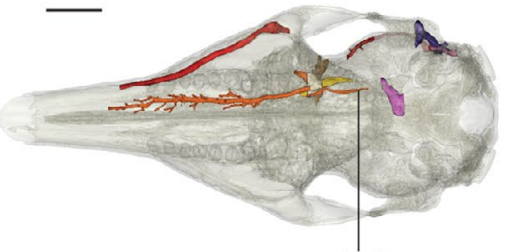

pbplc
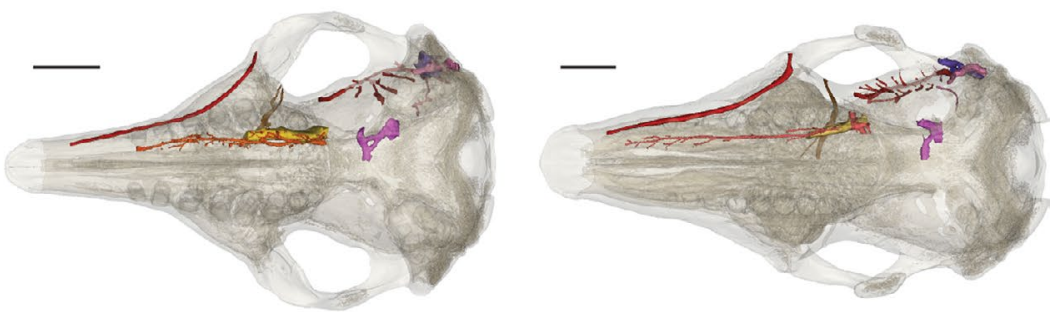

(adult stage)

FIGURE 5 Ontogenetic variation of internal canals selected in this study viewed in ventral view on transparent crania in each developmental series (Dasypus, Zaedyus and Cabassous). Note that early postnatal stages for Cabassous are not documented in our sample. See Le Verger et al., (2020) for the determination of stages. Phylogenetic relationships are indicated with colors following Figure S3. The color of canals follows that of Figure 1. Abbreviations: pbplc, posterior branch of the palatine canal. Scale $=1 \mathrm{~cm}$ 
In our adult sample, the canal is relatively straight, very thin, oriented posteromedially in dorsal view, and without ramifications in Bradypus (Figure 6). In Tamandua, Peltephilus, Stegotherium, Dasypus, Euphractus, Priodontes, and Cabassous, its overall course is transverse but with a posterior bend or convexity of varying degree (Figure 6). Ramifications and a posterior convexity are also found in Prozaedyus, Chaetophractus, Zaedyus, and Proeutatus, but the overall course of their canal is more anteromedially oriented, as is also observed in Stegotherium, Priodontes, and Cabassous (Figure 6). The same orientation is found in Doellotatus (incomplete), except that the course of the canal is completely straight and has no ramifications (Figure 6). Tolypeutes, on the other hand, show a very peculiar course with a forked structure in a dorsal view (Figure 6). The canal is merged with diploe in chlamyphorines, but its presence is observable in Calyptophractus, in which it has a straight and anteromedially oriented trajectory (Figure 6). This canal was not observed in Vassallia or in any of the glyptodonts sampled. However, Gaudin (2004) notes the presence of this canal in glyptodonts and Gaudin and Lyon (2017) mention it in the pampathere Holmesina (Simpson, 1930) (but see below). We suspect a taphonomic bias for some specimens (e.g., some glyptodonts) and call for a deeper study of this canal in cingulates before its variation can be scored.

\subsubsection{Nasolacrimal Canal}

The nasolacrimal canal originates posteriorly at the anterior orbital edge with the lacrimal foramen (Figure 1 and Figure S1). It runs anteriorly within the lacrimal and the maxillary bones in its posteriormost portion. More anteriorly, the canal is located between the inner wall
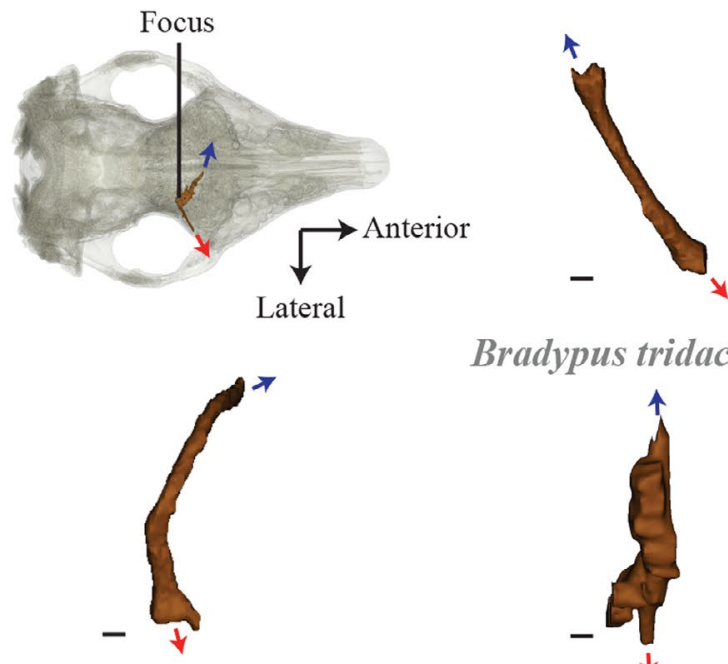

Stegotherium tauberi $\uparrow$

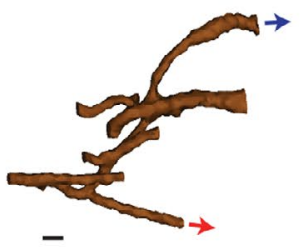

Chaetophractus villosus

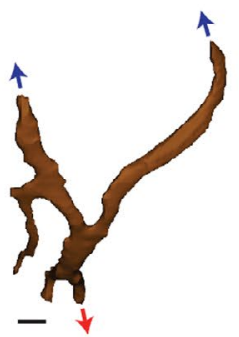

Tolypeutes tricinctus

\section{Bradypus tridactylus}

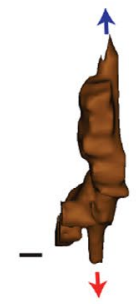

Dasypus novemcinctus

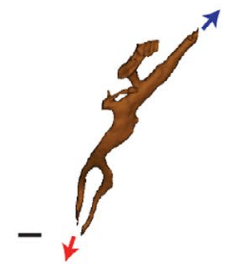

Zaedyus pichiy *

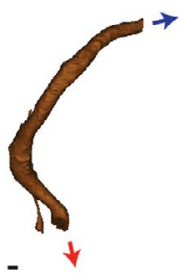

Priodontes maximus

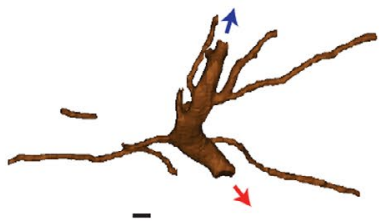

Tamandua tetradactyla

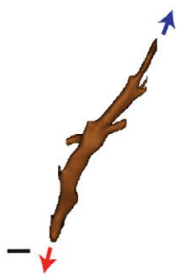

Prozaedyus proximus $\uparrow$

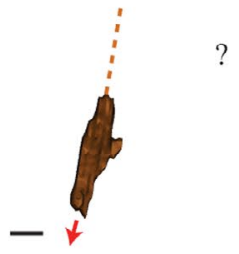

Doellotatus sp. †*

Cabassous unicinctus *

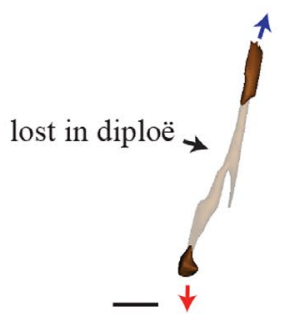

Calyptophractus retusus

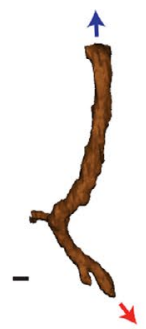

Peltephilus pumilus $\dagger$

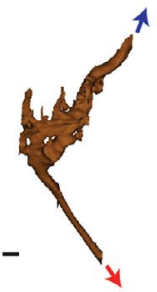

Euphractus sexcinctus
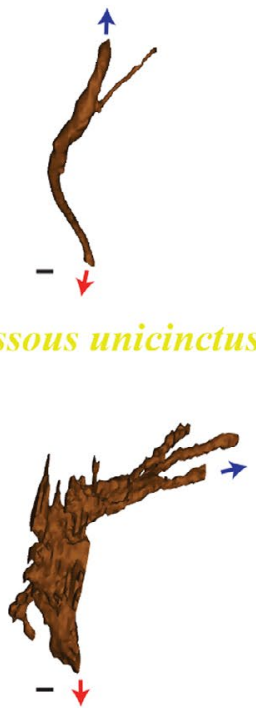

Proeutatus lagena $\uparrow$

FIGURE 6 Interspecific variation of the canal for the frontal diploic vein in our sample, all illustrated in dorsal view. Red arrows mark the main external opening of the canal. Blue arrows mark the main internal path of the canal on the cranial midline. Colors of species names follow Figure 2. Scale $=1 \mathrm{~mm}$ 
of the maxillary and turbinates. It opens anteriorly (in front of the tooth row, except in Peltephilus) and ventromedially into the nasal cavity (Figures S1E and S5). This canal allows the transmission of fluids from the lacrimal sac to the nasal cavity and is potentially accompanied by a vein in Euphractus (see Wible \& Gaudin, 2004).

The course of the nasolacrimal canal barely changes during ontogeny in our sample (Figures 3 and 5). Its length changes and follows the lengthening of the snout that accompanies the growth of the cranium (Le Verger et al., 2020). In addition, Cabassous and, to a lesser degree, the adult stage of Zaedyus show a more medial orientation of the course of the nasolacrimal canal in its most posterior part, which differs slightly from Dasypus and other stages of Zaedyus, where it runs more parallel to the external surface of the cranium (Figures 3 and 5).

The position of the nasolacrimal canal and lacrimal foramen varies among taxa, although this feature was not scored in previous matrices (e.g., Gaudin \& Wible, 2006). The lacrimal foramen is particularly high relative to the orbital edge (closer to the most dorsal point of the orbit than to the jugal bone in lateral view) in chlamyphorines, Proeutatus, and glyptodonts (Figure 7). The trajectory of the nasolacrimal canal is strongly sigmoid in Tamandua (Figure 7). In Bradypus, Peltephilus, Proeutatus, Euphractus, and Chaetophractus, the course of the nasolacrimal canal is slightly convex dorsally (Figure 7). The curvature is much pronounced in Vassallia in the posterior half of its course as it passes above the tooth row (Figure 7). In dasypodines, Prozaedyus, Zaedyus, tolypeutines, and chlamyphorines, the nasolacrimal canal is relatively straight or it bears a slight ventral convexity in its posterior part (Figure 7). In glyptodonts, the canal runs ventromedially and not anteriorly from the lacrimal foramen (Figures 7 and 8 ), and curves strongly inward anteriorly when approaching the sagittal plane of the cranium (Figures 7 and 8).

Whereas glyptodonts appear to show a unique condition in the course of their nasolacrimal canal, the anterior opening of this canal is located halfway up in their nasal cavity as in Bradypus, Tamandua, Peltephilus, Doellotatus, Proeutatus, and Vassallia. In comparison, this opening is closer to the palate in other specimens (Figure 7). This variation can be scored in the following character (see Table 2).

Character 3 (discrete-unordered): Anterior opening of the nasolacrimal canal in nasal cavity.

State (0): Halfway up in the nasal cavity.

State (1): Ventral in the nasal cavity, close to the palate.

\subsection{3 | Palatine and sphenopalatine canals}

Two large canals are enclosed within the maxillary and palatine bones forming the hard palate in cingulates: the palatine canal and the sphenopalatine canal (Figure 1 and S1) (Wible \& Gaudin, 2004). The palatine canal is generally thinner, longer than, and positioned medial to the sphenopalatine canal. The palatine canal transmits the major and minor palatine nerve, artery, and vein in Euphractus (Wible \& Gaudin, 2004). This canal opens externally at the caudal palatine foramen posteriorly and at the multiple foramina scattered throughout the hard palate (both in the palatine and maxillary) anteriorly (Figure S1). The sphenopalatine canal, which is often very wide in cingulates, transmits the caudal nasal nerve and the sphenopalatine artery and vein (Wible \& Gaudin, 2004). The sphenopalatine canal opens anteriorly in the nasal cavity and posteriorly in the pterygopalatine fossa just posterior to the dental row and close to or confluent with the caudal palatine foramen (Wible \& Gaudin, 2004; Figure S1). The palatine canal and sphenopalatine canal are confluent in part of their posterior course in many of the species in our sample.

The palatine canal and sphenopalatine canal vary little during ontogeny within the three species of our ontogenetic series (Figures 3 and 5). The branch of the palatine canal posterior to its region of confluence with the sphenopalatine canal in Dasypus and Cabassous appears in the subadult (or intermediate) stage and elongates further in the adult stage (Figures 3 and 5). In the youngest specimen of Zaedyus, the sphenopalatine canal is much wider relative to cranium size than in later stages, and there is no region of confluence with the palatine canal (Figures 3 and 5). In the youngest Dasypus specimen, the sphenopalatine canal is absent. It is present only as a wide groove in the youngest to subadult stages but is completely enclosed in the adult stage of Dasypus in our sample (Figures 3 and 5).

In our adult sample, the shape and trajectory of the palatine canal do not vary much among species (Figures 7 and 8). In glyptodonts, the palatine canal strongly ascends posteriorly (starting from Mf6) (Figure 7) and forms a groove running along the inner wall of the nasopharyngeal canal (Figure S6). In other cingulates, the palatine canal does not show such an ascending trajectory posteriorly. The sphenopalatine canal, which is thicker than the palatine canal, features a relatively straight trajectory in lateral view in Peltephilus, dasypodines, Prozaedyus, Doellotatus, Euphractus, Zaedyus, and "Cochlops," whereas it shows a strong ventral curvature in Chaetophractus, tolypeutines, chlamyphorines, and Glyptodon (Figure 7). It should be further noted that the dorsal position of the sphenopalatine canal relative to the nasopharyngeal canal is a feature shared by Vassallia and Glyptodon (Figure S7). In Bradypus and Tamandua, the palatine canal does not contact the sphenopalatine canal (Figures 7 and 8). The two canals are in contact in a small region of confluence in the dasypodines whereas the palatine canal becomes completely confluent with the sphenopalatine canal, and sometimes accompanied by ventrally oriented auxiliary branches of the palatine canal, in Peltephilus, tolypeutines, chlamyphorines, and Glyptodon (Figures 7 and 8). In extant euphractines, the confluence between the sphenopalatine canal and the palatine canal is not as clear-cut as in the above-cited cingulates (Figures 7 and 8). The palatine canal of euphractines runs ventrally along the sphenopalatine canal in the same figure eight-shaped canal while being completely conjoined only in their most posterior part and at their posterior opening (Figures 7 and 8). The extent of this confluence is highly variable in Euphractus according to Wible and Gaudin (2004) and in other cingulates as well (Gaudin \& Wible, 2006-character 71). We observed the same variation as Gaudin and Wible (2006) concerning the extent of this confluence in the vicinity of the posterior opening 

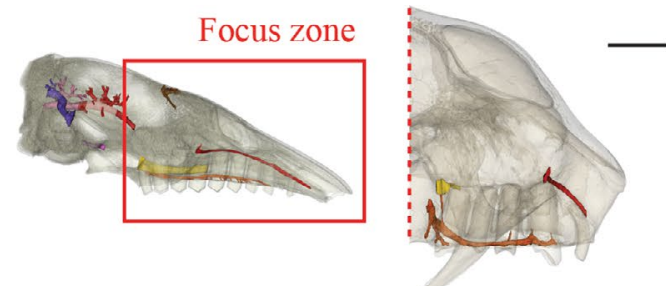

Bradypus tridactylus

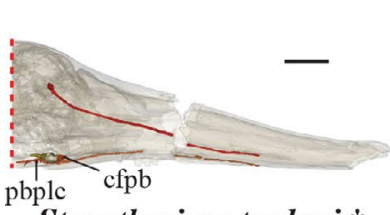

Stegotherium tauberi $\uparrow$

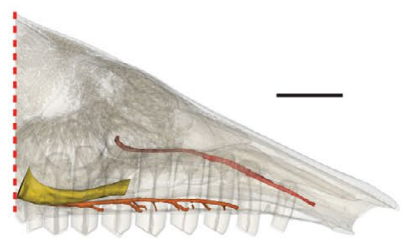

Chaetophractus villosus
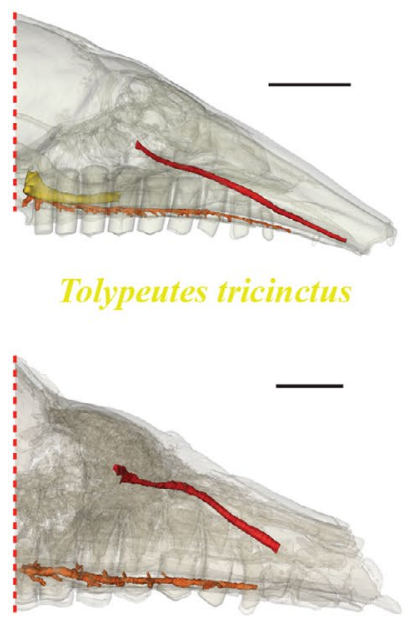

Proeutatus lagena $\dagger$

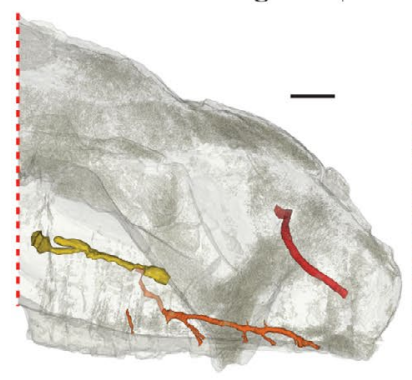

Vassallia maxima $\uparrow$

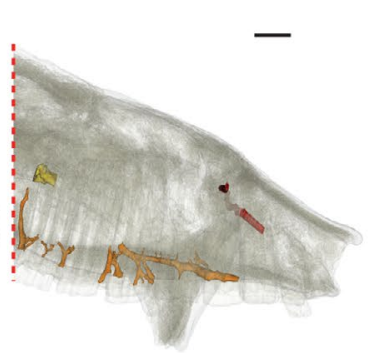

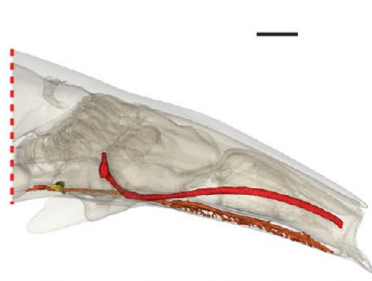

Tamandua tetradactyla

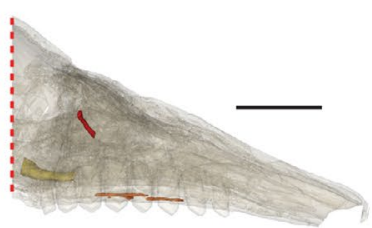

Prozaedyus proximus $\dagger$

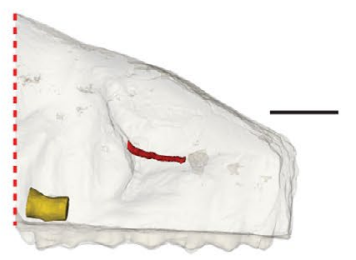

Doellotatus sp. †*

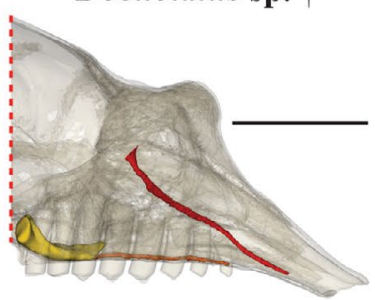

Chlamyphorus truncatus

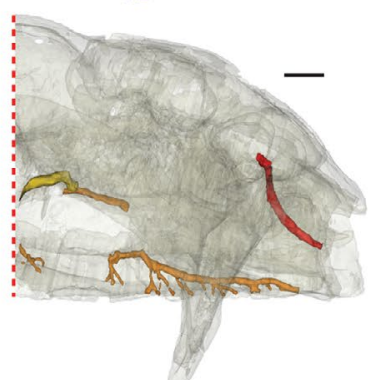

«Metopotoxus » anceps $\dagger$

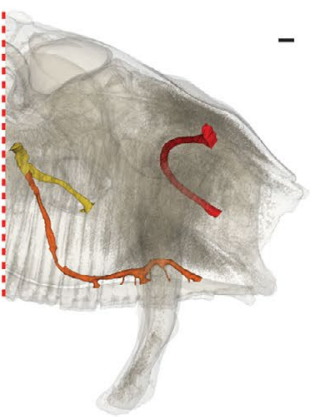

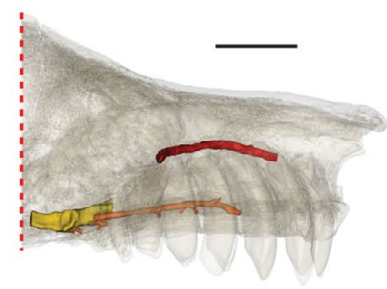

Peltephilus pumilus $\dagger$

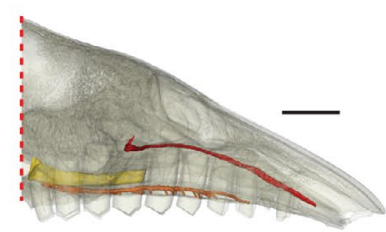

Euphractus sexcinctus
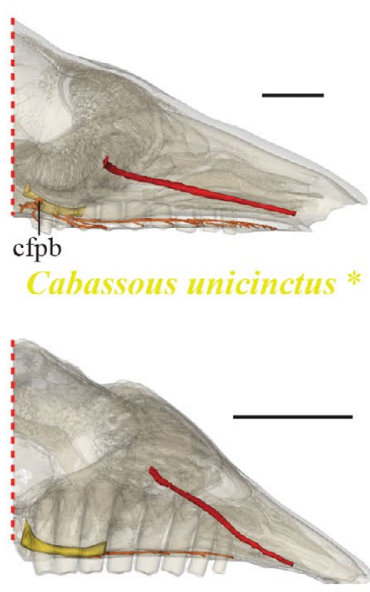

Calyptophractus retusus

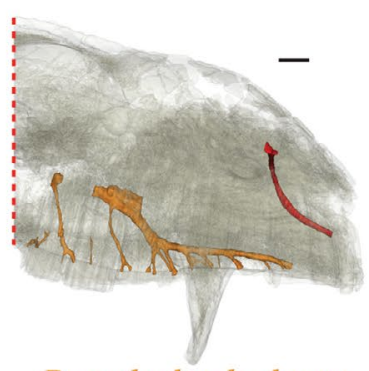

Propalaehoplophorus minus $\dagger^{*}$

Orientation:

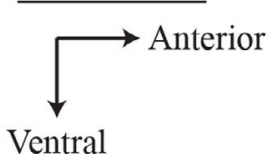

\section{«Cochlops » debilis †* Eucinepeltus complicatus $\uparrow \quad$ Glyptodon sp. $\dagger^{*}$}

FIGURE 7 Interspecific variation in our sample of the reconstructed nasolacrimal (= red), sphenopalatine (= yellow) and palatine (= orange) canals shown in lateral view. Crania are reconstructed with transparency. Colors of species names follow Figure 2 . Abbreviations: $\mathrm{cfpb}$, caudal foramen for palatine canal branch; pbplc, posterior branch of palatine canal. Scale $=1 \mathrm{~cm}$ 

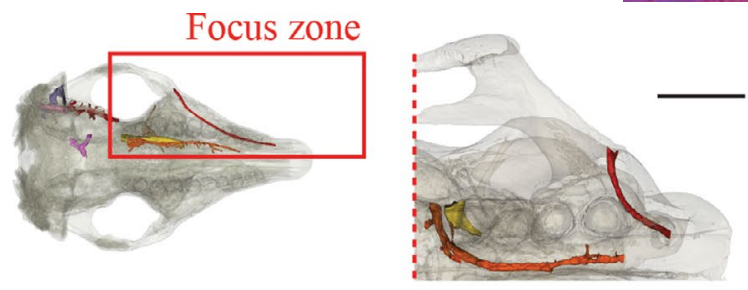

Bradypus tridactylus
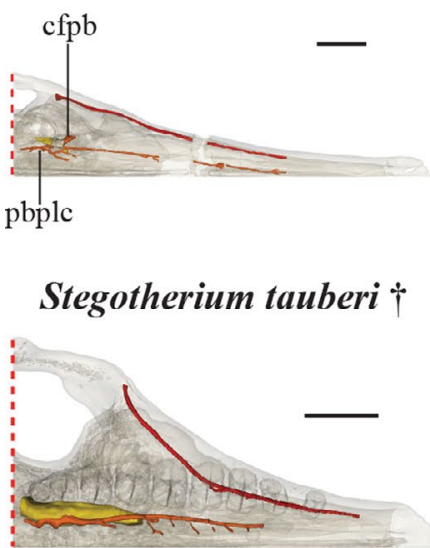

Chaetophractus villosus

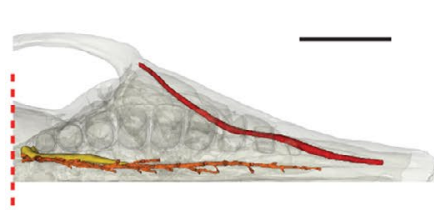

Tolypeutes tricinctus

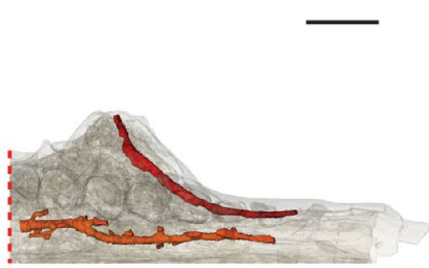

Proeutatus lagena $\dagger$

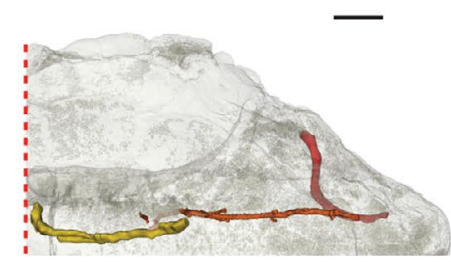

«Cochlops » debilis †*

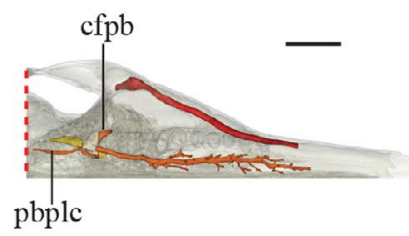

Dasypus novemcinctus

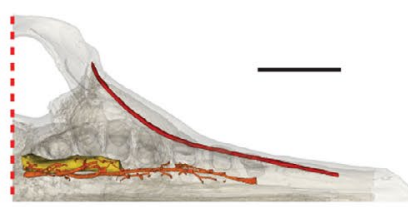

Zaedyus pichiy *

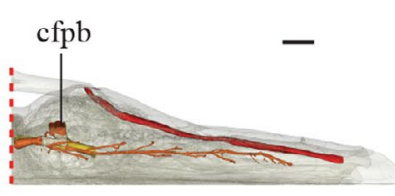

Priodontes maximus

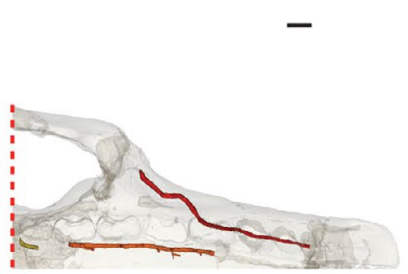

Vassallia maxima $\dagger$

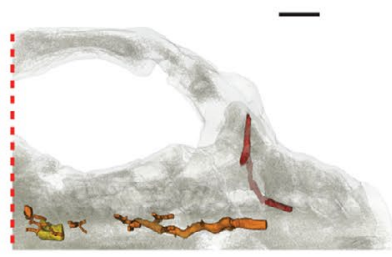

Eucinepeltus complicatus $\uparrow$

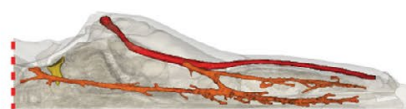

Tamandua tetradactyla

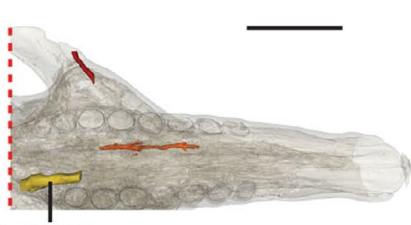

left side

Prozaedyus proximus $\dagger$

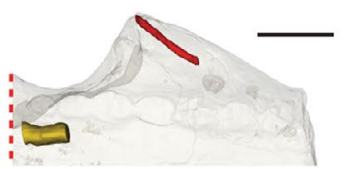

Doellotatus sp. †*

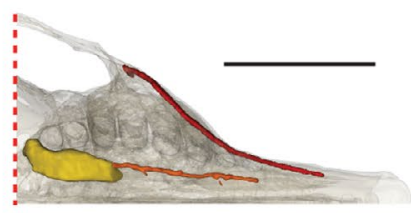

Chlamyphorus truncatus

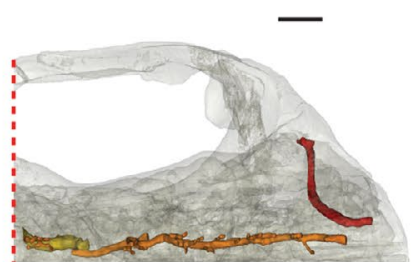

«Metopotoxus » anceps $\dagger$

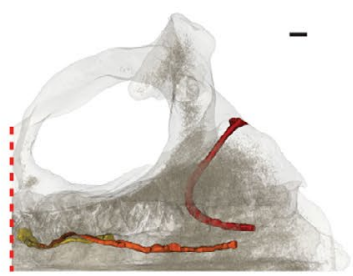

Glyptodon sp. $\dagger^{*}$

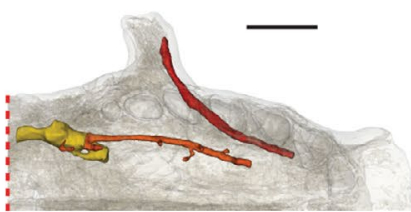

\section{Peltephilus pumilus $\dagger$}

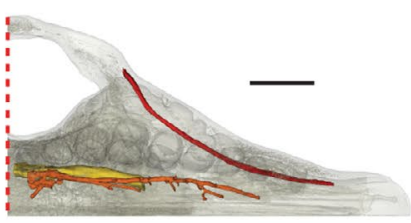

Euphractus sexcinctus

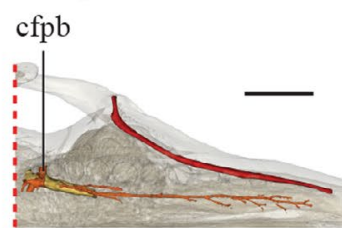

Cabassous unicinctus *

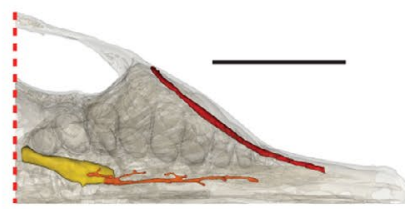

Calyptophractus retusus

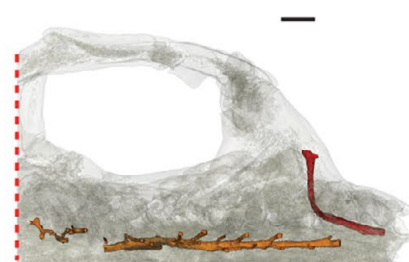

Propalachoplophorus minus $\dagger^{*}$

Orientation:

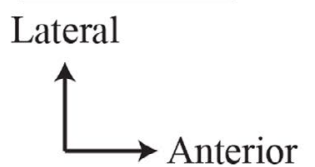

FIGURE 8 Interspecific variation in our sample of the reconstructed nasolacrimal (= red), sphenopalatine (= yellow) and palatine (= orange) canals shown in ventral view. Crania are reconstructed with transparency. Colors of species names follow Figure 2. Abbreviations: $\mathrm{cfpb}$, caudal foramen for palatine canal branch; pbplc, posterior branch of palatine canal. Scale $=1 \mathrm{~cm}$ 
of the sphenopalatine canal for all the taxa in our sample. Several branches may emerge from this region of confluence (Figures 7 and 8), some of which present an interesting pattern. One branch opens externally from the caudal foramen of the palatine canal in dasypodines, Priodontes, and Cabassous (Figures 7 and 8). A second branch extends posteriorly into the hard palate before disappearing in the bone diploe in dasypodines. In Euphractus, Zaedyus, Priodontes, and Cabassous, two or more branches extend posteriorly into the hard palate, but they open in the nasopharyngeal canal (Figures 7 and 8). Several other ramifications of the palatine canal are present in our sample, but it remains to be determined how variable these are at the intraspecific level with a data set larger than that of Table S1.

Based on the observation of these two canals, we proposed to scrutinize evolutionary scenarios for the following character (see Table 2).

Character 4 (discrete-unordered): Sphenopalatine and palatine canal connection.

State (0): No contact.

State (1): Partial contact, with palatine canal running ventrally along the sphenopalatine canal and producing posterior branches.

State (2): Complete fusion.

\subsection{4 | Transverse Canal}

When present, the transverse canal is marked externally by a foramen positioned anteroventrally to or within the foramen ovale in the alisphenoid (Figure S1). This canal crosses the cranium transversally at the level of the basisphenoid and transmits a large vein issued from the cavernous sinus (Sánchez-Villagra \& Wible, 2002; Wible \& Gaudin, 2004). Often, one or more branches originate from this canal and extend posteriorly toward the lateral edge of the basisphenoid to join the inferior petrosal sinus (Wible \& Gaudin, 2004).

The transverse canal appears early in Dasypus and varies little during ontogeny. Although, in Zaedyus and Cabassous, the connection between the transverse canal and the posterior branch extending toward the inferior petrosal sinus varies in both series, we have not observed a clear ontogenetic pattern of variation in our three species (Figures 3 and 5).

In Bradypus, Peltephilus, Stegotherium, Doellotatus, Tolypeutes, and Glyptodon, there is no transverse canal, or it is not detectable (scored as present in Doellotatus and Stegotherium, variable in Tolypeutes by Gaudin \& Wible, 2006-character 111). Chlamyphorines have a transverse canal foramen opening directly within the braincase, and thus there is a very short canal that does not cross the midline of the cranium. Tamandua stands out in having a thin lateral part of the transverse canal which differs markedly from the condition in Cingulata (Figure 9). In Tamandua, Dasypus, Prozaedyus, extant euphractines, Priodontes, and Cabassous, the branch starting from the transverse canal foramen is oriented posteromedially in ventral view (Figure 9). In the Miocene glyptodonts, it is medially oriented (Figure 9). In Vassallia, it is anteromedially oriented (Figure 9). This lateral branch of the transverse canal splits into a branch that crosses the midline in the basisphenoid bone and a branch that joins the inferior petrosal sinus (Figure 9). In Proeutatus, this bifurcation occurs much closer to the transverse canal foramen than in other taxa (Figure 9). It is relatively more medial in Prozaedyus, extant euphractines, Priodontes, and Cabassous (Figure 9). In Tamandua, Dasypus, Vassallia, and Miocene glyptodonts, this bifurcation is closer to the sagittal plane than to the foramen (Figure 9). The transverse medial branch is anteromedially oriented in ventral view in Prozaedyus, Euphractus, and Proeutatus, whereas it is medially oriented in the other taxa (Figure 9). Our specimens of Tamandua, extant euphractines (not complete in Chaetophractus), and Priodontes show an additional branch connecting the transverse medial branch to the posterior branch reaching the inferior petrosal sinus (Figure 9). In Vassallia and the Miocene glyptodonts, the posterior branch reaching the inferior petrosal sinus is much thinner than the rest of the canal, in contrast to the other taxa, in which the whole canal exhibits a relatively homogeneous width (Figure 9).

Based on these observations of the transverse canal, we propose to scrutinize evolutionary scenarios for the following character (see Table 2).

Character 5 (discrete-unordered): Orientation of the branch starting from the transverse canal foramen.

State (0): Posteromedial.

State (1): Medial or anteromedial.

State (2): No canal.

\subsection{5 | Orbitotemporal and posttemporal canals}

Within the braincase, the orbitotemporal canal provides a passageway to the rostral extension of the ramus superior of the stapedial artery, or orbitotemporal artery (giving rise to the ramus supraorbitalis in the orbital region), and a few small veins (Wible \& Gaudin, 2004), whereas the more posterior posttemporal canal transmits the arteria diploëtica magna and the large vena diploëtica magna (Wible, 1987; Wible \& Gaudin, 2004). These two canals can give rise to the arterial and venous rami temporales along the lateral wall of the braincase, which exit via numerous foramina on the cranial roof to irrigate the temporalis muscle (Wible \& Gaudin, 2004; Figure S1). The posttemporal canal is connected posteriorly to an external groove in the petro-occipital region marking the passage of the occipital artery (Wible \& Gaudin, 2004; Figure S1). From there, the posttemporal canal extends forward as a canal enclosed between the petrosal and squamosal (or only in the squamosal) and is oriented mostly horizontally. More anteriorly, past the petrosal, the posttemporal canal is connected to the orbitotemporal canal, which runs further anteriorly within or on the inner surface of the lateral braincase wall (formed by the squamosal, frontal, and sometimes the parietal). The delimitation between the two canals generally occurs where the canal for the ramus superior joins them (Muizon et al., 2015). However, we were only able to observe a canal possibly transmitting the ramus superior in Tolypeutes (Figure S8) but not in the other specimens. Consequently, we followed the suggestion of Wible and Gaudin 

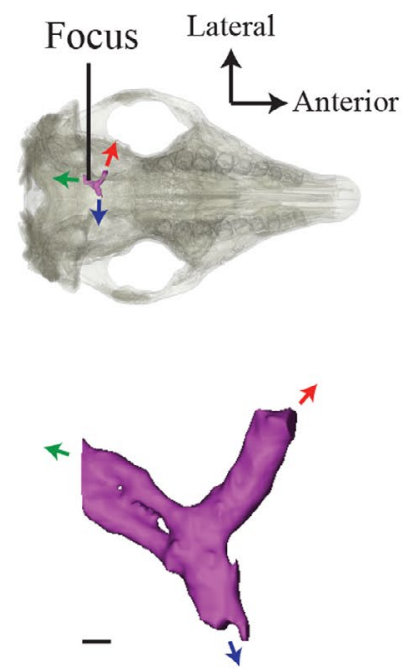

Euphractus sexcinctus

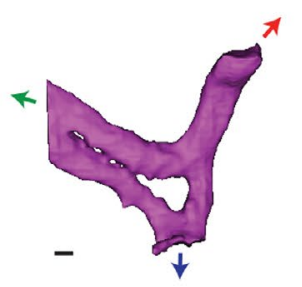

Priodontes maximus

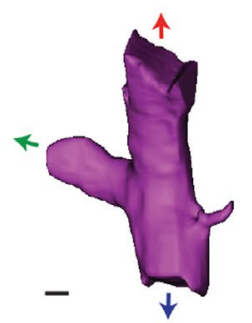

\section{Propalaehoplophorus minus $\dagger^{*}$}

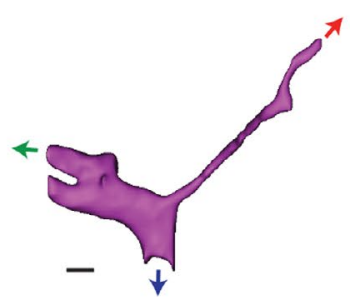

Tamandua tetradactyla

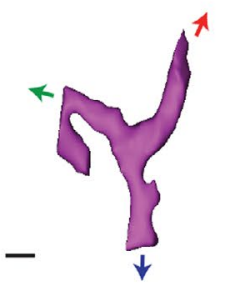

Chaetophractus villosus

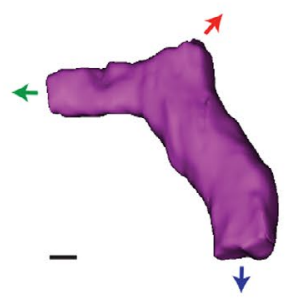

Proeutatus lagena $\uparrow$

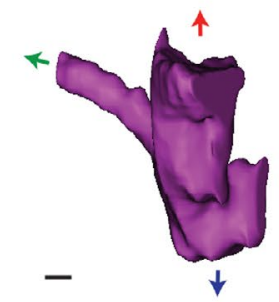

《Cochlops 》 debilis †*

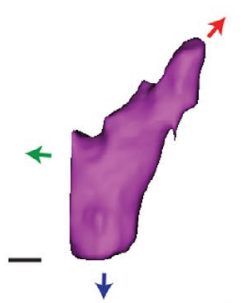

Dasypus novemcinctus

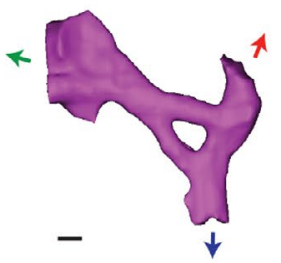

Zaedyus pichiy *

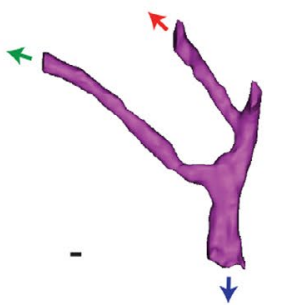

Vassallia maxima $\dagger$

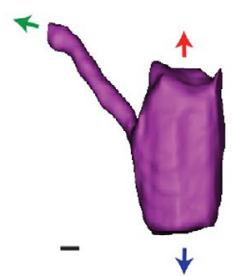

Eucinepeltus complicatus $\uparrow$

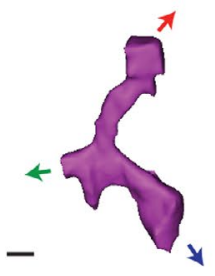

Prozaedyus proximus $\dagger$

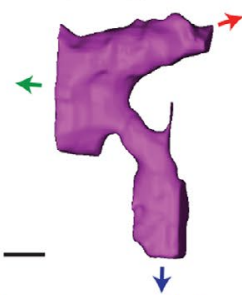

Cabassous unicinctus *

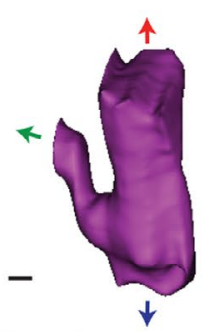

«Metopotoxus » anceps $»$

FIGURE 9 Interspecific variation of the transverse canal in ventral view in our sample. Red arrows mark the main external opening of the canal. Blue arrows mark the branch crossing the midline. Green arrows mark the main posterior branch which connects to the inferior petrosal sinus (see text). Colors of species names follow Figure 2. Scale $=1 \mathrm{~mm}$

(2004), who separate the two canals at the level of the postglenoid foramen. In some taxa, the orbitotemporal canal is not completely enclosed for parts of its length and appears instead as a groove on the internal wall of the braincase. The anterior opening of the orbitotemporal canal is located in the orbitotemporal region, just posteroventral to the postorbital constriction (Figure S1; Wible \& Gaudin, 2004; = cranioorbital foramen in Gaudin \& Wible, 2006; see also Muizon et al., 2015 for multiple illustrations of these canals in another placental taxon).

The orbitotemporal canal only appears as a short canal near the orbitotemporal region in the youngest specimens of all three species, whereas the canal (or groove) is clearly visible for its entire length in later stages (Figures 3 and 5). The connections of the orbitotemporal canal with canals for the numerous rami temporales occur in the two last stages in both Zaedyus and Cabassous (Figures 3 and 5). The posttemporal canal is already well formed in the youngest specimen of Dasypus and hardly changes during ontogeny (Figures 3 and 5). In Zaedyus, the posttemporal canal is not enclosed in the youngest stage. In Cabassous, the posttemporal canal is present in the youngest stage sampled, but it expands anteriorly during the two subsequent stages (Figures 3 and 5).

In our adult sample, Bradypus, Tamandua, extant euphractines, Vassallia, and glyptodonts possess a posttemporal canal emerging at the center of the occiput in lateral view and at the level of the jugular foramen (Figure 10). In Peltephilus, it originates more ventrally, even with the most dorsal margin of the occipital condyles in lateral view (Figure 10). In dasypodines, tolypeutines, and chlamyphorines, the posterior extremity of the canal is at an intermediate height 
Focus zone
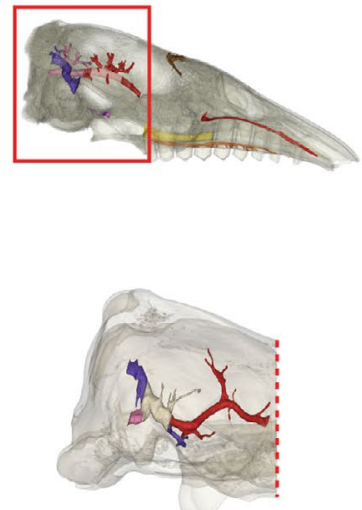

Stegotherium tauberi $\uparrow$

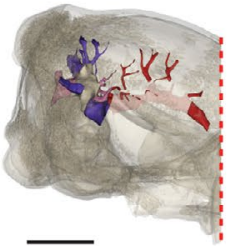

Chaetophractus villosus

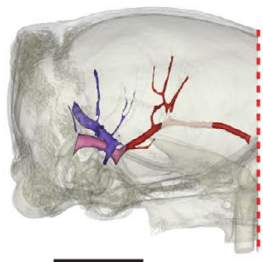

Tolypeutes tricinctus

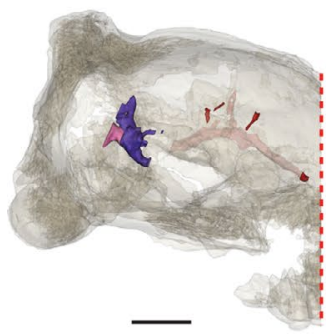

Proeutatus lagena $\pitchfork$

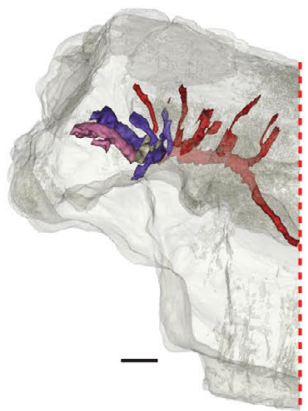

«Cochlops » debilis †*

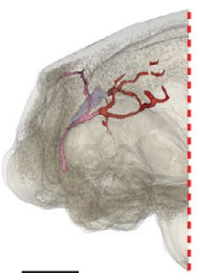

Bradypus tridactylus

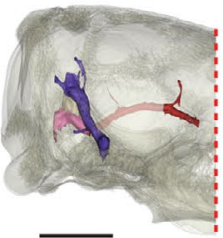

Dasypus novemcinctus

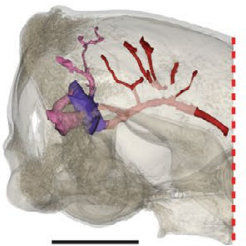

Zaedyus pichiy *

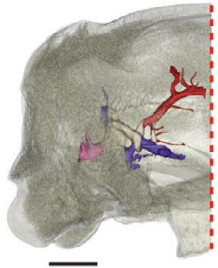

Priodontes maximus

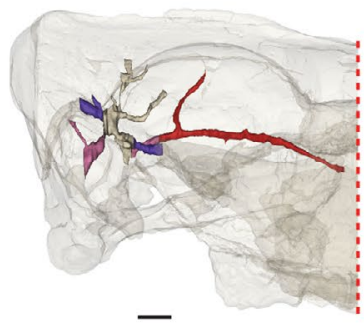

Vassallia maxima $\uparrow$

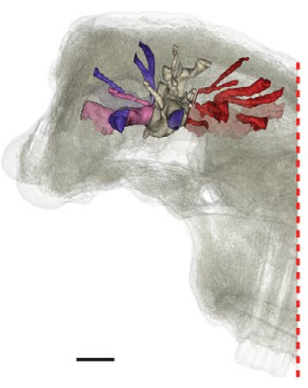

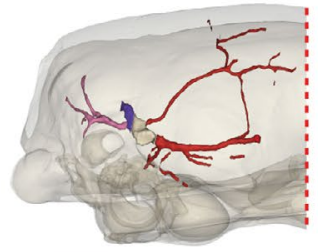

Tamandua tetradactyla

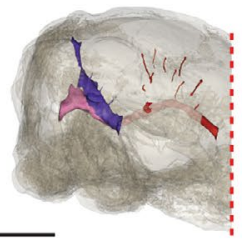

Prozaedyus proximus $\dagger$

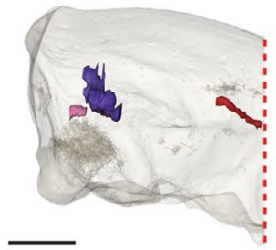

Doellotatus sp. $\uparrow^{*}$

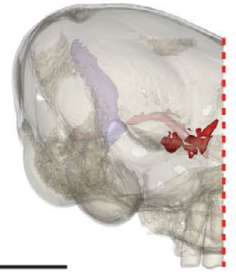

Chlamyphorus truncatus

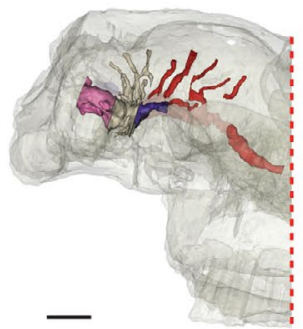

«Metopotoxus 》 anceps

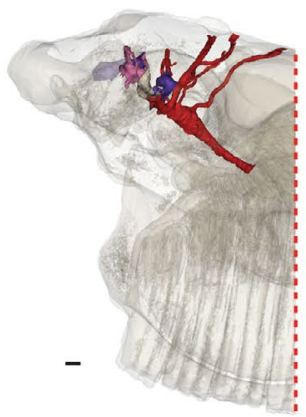

Glyptodon sp. †*

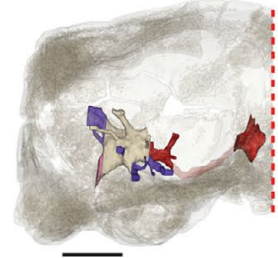

Peltephilus pumilus †

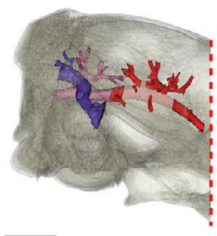

Euphractus sexcinctus

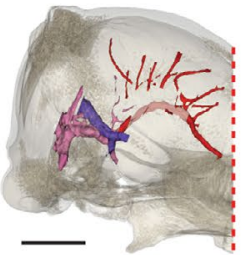

Cabassous unicinctus *

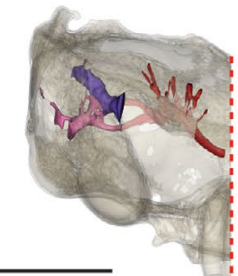

Calyptophractus retusus

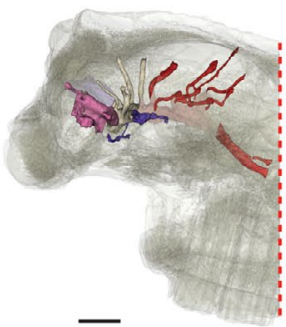

Propalaehoplophorus minus ${ }^{+*}$

Orientation:

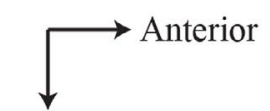

Ventral

FIGURE 10 Interspecific variation in our sample of the orbitotemporal (= red), posttemporal (= pink) and capsuloparietal emissary vein (= blue) canals shown in lateral view. Caudal part of the cranium is transparent. Parts of the canals showing transparency symbolize a groove instead of a fully enclosed canal. Colors of species names follow Figure 2 . Scale $=1 \mathrm{~cm}$ 
(Figure 10). Apart from the position of the posterior opening of this canal (= posttemporal foramen of Wible \& Gaudin, 2004), we were unable to determine any systematically significant variation regarding its direction, length, or width.

In Bradypus and Tamandua, the orbitotemporal canal does not reach the orbitotemporal region (Figures 10 and 11). It reaches the orbitotemporal region in all the cingulates in our sample except for Priodontes (Figures 10 and 11). Gaudin and Wible (2006) mention the absence of the anterior opening of the orbitotemporal canal not only in Priodontes (character 78) but also in Chlamyphorus and Vassallia for which we observe a clear opening in the orbitotemporal region (Figure 10). In Bradypus, Tamandua, and Peltephilus, this canal bears a ventral curvature (strong in Peltephilus), whereas its trajectory exhibits a more or less strong dorsal curvature in all the other taxa (Figure 10). In Peltephilus, Dasypus, Prozaedyus, extant euphractines, Tolypeutes, Cabassous, chlamyphorines, Proeutatus, and Miocene glyptodonts, the orbitotemporal canal becomes a groove on the internal lateral wall of the braincase before being enclosed again as a canal close to its external anterior opening (Figure 10). In Calyptophractus, Proeutatus, and glyptodonts, the anterior half of the orbitotemporal canal displays a pronounced downward trajectory, and its anterior opening is located lower than its posterior connection with the posttemporal canal (Figure 10). Calyptophractus stands out, however, in having two branches that connect the orbitotemporal and posttemporal canals (Figure 10). A large region of confluence between the orbitotemporal and posttemporal canals and the canal for the capsuloparietal emissary vein is identified in Tamandua, Peltephilus, Stegotherium, Dasypus, Chaetophractus, Priodontes, Vassallia, and the glyptodonts (and potentially also in Proeutatus but the orbitotemporal canal is not distinct in this region; Figures 10 and 11). This confluent region is reminiscent of the petrosquamosal fossa in Alcidedorbignya, Muizon \& Marshall, 1987 (Muizon et al., 2015). The orbitotemporal and posttemporal canals connect with the rami temporales through multiple small canals whose number remains quite variable at the intraspecific level. However, a high density of rami temporales for the orbitotemporal canal is particularly noticeable in extant euphractines, Cabassous, Calyptophractus, and glyptodonts (Figure 10). This density is coded by Gaudin and Wible (2006), who counted the number of foramina for rami temporales in the temporal fossa of parietal ( 0 , equal to or less than five; 1 , greater than five-character 97).

In their matrix, almost all cingulates are coded as having more than five foramina. The variations in the density of the canals for the rami temporales observed in our study call for further investigation of these structures, which could potentially carry an interesting phylogenetic signal among cingulates.

Based on these observations of the orbitotemporal canal, we propose to scrutinize evolutionary scenarios for the following character (see Table 2).

Character 6 (discrete-unordered): Downward trajectory of the orbitotemporal canal.

State (0): Canal does not reach the orbitotemporal region.
State (1): The anterior part of the canal has a slight downward trajectory ending at the same or almost the same height as its origin from the posttemporal canal.

State (2): The canal has a strong downward anterior trajectory, and its anterior opening is much lower than its posterior connection to the posttemporal canal.

\subsubsection{Canal of the Capsuloparietal Emissary Vein}

The canal for the capsuloparietal emissary vein opens anteroventrally at the postglenoid and suprameatal foramina and connects to the groove for the transverse sinus posterodorsally (Muizon et al., 2015; Wible, 1993). From the cranial roof, the transverse sinus runs lateroventrally in a wide groove excavated in the inner surface of the parietal and extends anteroventrally within a canal formed by the petrosal medially and the squamosal laterally. This canal opens externally through the suprameatal foramen, the postglenoid foramen and accessory foramina at the posterior base of the zygomatic arch (e.g., Wible \& Gaudin, 2004; Figure S1). It transmits the capsuloparietal emissary vein (= retroarticular vein in Canis, Linnaeus 1758 (Evans \& de Lahunta, 2012); postglenoid vein in Cynocephalus, Boddaert, 1768 (Wible, 1993), and Dasypus, Linnaeus 1758 (Wible, 2010)). In our sample, this canal is often partly confluent with the posttemporal and orbitotemporal canal in its posterodorsal portion (Figure S9).

The canal for the capsuloparietal emissary vein is already well formed in the youngest specimen of Dasypus and hardly changes during ontogeny, except that it becomes relatively thinner (Figures 3 and 5). In Zaedyus, it is only partly formed in the youngest specimen, and its trajectory is better marked in older stages (Figures 3 and 5). In the youngest Cabassous, this canal is noticeably short and only marked in its most ventral part (glenoid region). It is only in older stages that the canal elongates posterodorsally (Figures 3 and 5).

The canal is absent and the passage of the vein is only indicated by a groove in Bradypus and Chlamyphorus. The groove is very wide in the latter two (Figure 10). The canal of the capsuloparietal emissary vein opens through the postglenoid foramen and potentially in the suprameatal foramen as well (see rami temporales opening in the squamosal whose number varies in our intraspecific sampling, Table S1) in Peltephilus, Prozaedyus, Doellotatus, extant euphractines, chlamyphorines, Proeutatus, Vassallia, and the glyptodonts (as notably scored for the glenoid region by Gaudin \& Wible, 2006-character 119; Figures 10 and 11). In tolypeutines, the canal always opens by a suprameatal foramen with a well-marked branch, whereas its opening via the postglenoid foramen may sometimes be absent, as we have occasionally observed the absence of a postglenoid foramen in our intraspecific sample of Cabassous (Table S1). For all our taxa except Bradypus, the canal extends anteroventrally from the cranial roof (Figure 10). However, its inclination varies considerably from one species to another. It is steeply inclined in dasypodines, slightly less so in Prozaedyus, Doellotatus, extant euphractines, and Proeutatus, and much less so in tolypeutines, Calyptophractus, 


\section{Focus zone}
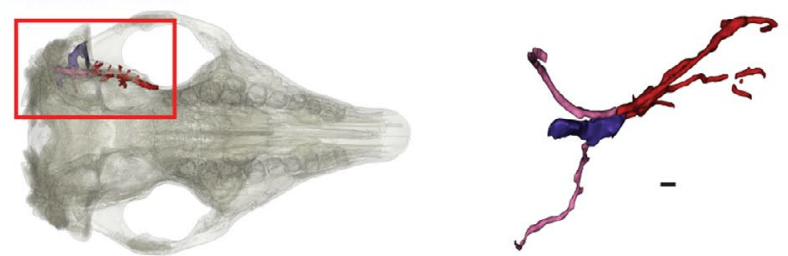

Bradypus tridactylus

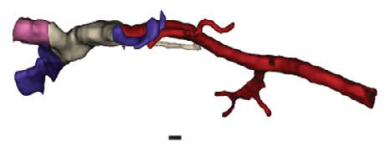

Stegotherium tauberi $\uparrow$

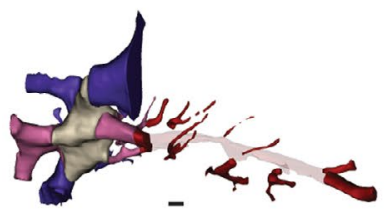

Chaetophractus villosus

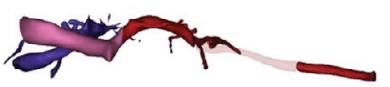

Tolypeutes tricinctus
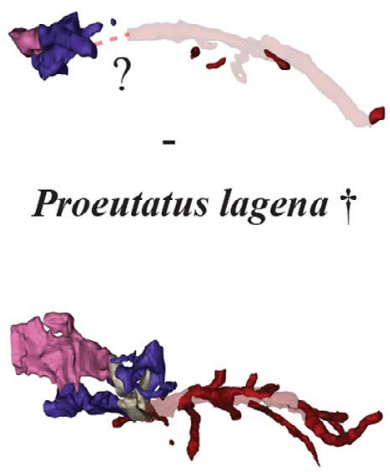

«Cochlops » debilis †*

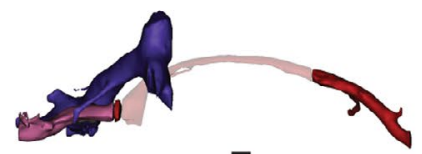

Dasypus novemcinctus

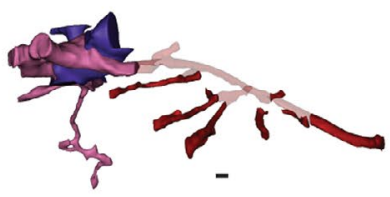

Zaedyus pichiy *

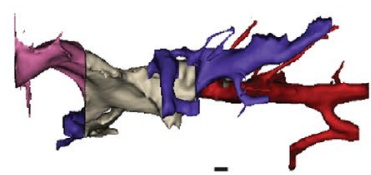

Priodontes maximus

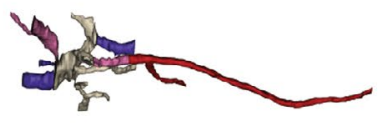

Vassallia maxima $\uparrow$

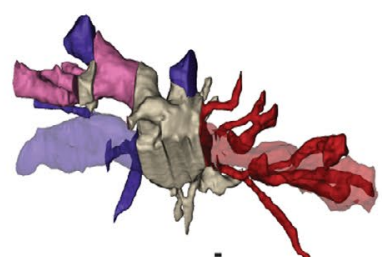

Eucinepeltus complicatus

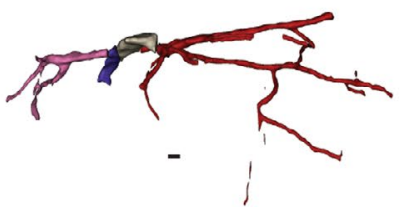

Tamandua tetradactyla

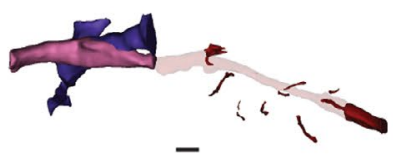

Prozaedyus proximus $\dagger$

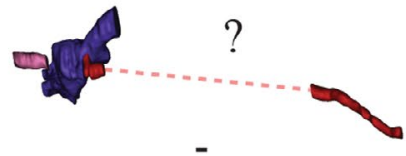

Doellotatus sp. $\uparrow^{* *}$

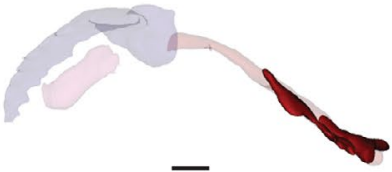

Chlamyphorus truncatus

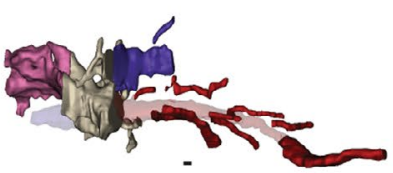

«Metopotoxus 》 anceps $\dagger$

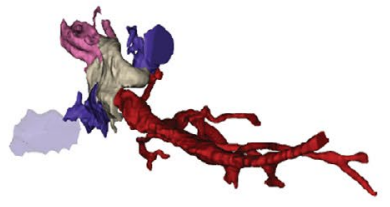

Glyptodon sp. †*

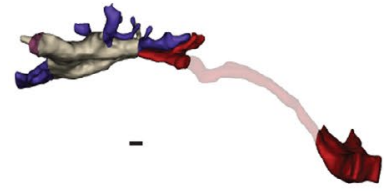

Peltephilus pumilus $\dagger$

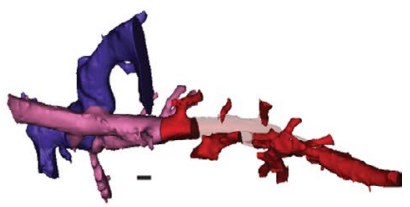

Euphractus sexcinctus

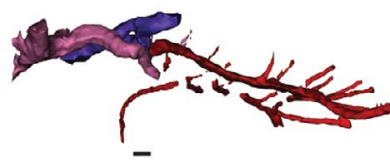

Cabassous unicinctus*

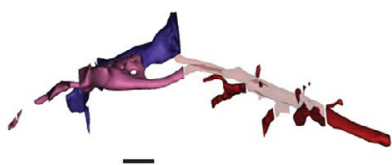

Calyptophractus retusus

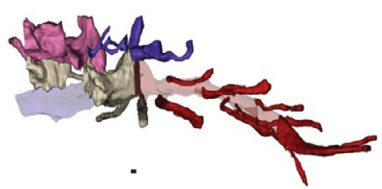

Propalaehoplophorus minus $\uparrow *$

\section{Orientation:}

Lateral

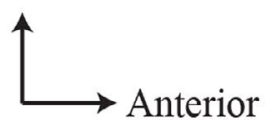

FIGURE 11 Interspecific variation in our sample of the orbitotemporal (= red), posttemporal (= pink) and capsuloparietal emissary vein (= blue) canals shown in ventral view. Transparent parts of the canals indicate a groove instead of a fully enclosed canal. Colors of species names follow Figure 2. Scale $=1 \mathrm{~mm}$

Vassallia and glyptodonts (Figure 10). The canal is sinuous in Euphractus and Chaetophractus. In glyptodonts, the canal even has an almost anteroposterior orientation near its anterior opening (Figures 10 and 11). The canal (or groove) for the capsuloparietal emissary vein reaches a region of confluence (= petrosquamosal fossa, Muizon et al., 2015) with the other canals of the braincase in Tamandua, Peltephilus, dasypodines (particularly thin in Dasypus), Chaetophractus, Priodontes, Vassallia, and glyptodonts (Figures 10 and 11). For the other taxa, the canal for the capsuloparietal emissary vein is only adjacent to the other canals (Figures 10 and 11-see Figure S9 for an illustration of the different cases in our sample). The variation in length and thickness of this canal does not provide 
clear systematic information. A relatively short canal is present in Tamandua, Doellotatus, Zaedyus, and Proeutatus compared with dasypodines (Figure 10). Chlamyphorines and Zaedyus show a relatively thicker canal compared with the very thin canal in Vassallia. The fact that small taxa have a relatively thicker canal is reminiscent of young specimens of Dasypus compared to older and larger specimens of the same species (Figures 3 and 5) and suggest a potential allometric pattern.

Based on these observations, we propose to scrutinize evolutionary scenarios for the following character related to the anterolateral extremity of the canal (see Table 2).

Character 7 (discrete-unordered): Canal of the capsuloparietal emissary vein inclination in lateral view.

State (0): Anterodorsal orientation or canal very short.

State (1): Inclination anteroventral from the posterior opening to the anterior opening.

State (2): Less anteroventrally inclined, with an almost anteroposterior orientation close to the anterior opening.

\subsection{Inclination of the cranial roof}

Digital study of the braincase of our sample enabled observation of notable variations in the internal vault inclination (= IVI) relative to the anteroposterior axis of the cranium. The values of the IVI angle (see Materials and Methods) show an interesting pattern in our sample that does not correlate $\left(R^{2}=0.1768 ; P\right.$-value $\left.=0.3246\right)$ with size (Figure 12). Whereas Glyptodon is distinguished from the other cingulates by an exceedingly high inclination combined with a large size, the large-sized Vassallia has a very low cranial roof inclination (Figure 12). Dasypus (adult specimen), Stegotherium, Chlamyphorus, Proeutatus, and Miocene glyptodonts are also characterized by high inclinations (Figure 12). The juvenile Cabassous also displays a strong inclination, which decreases with age, whereas the inclination increases with age in Dasypus (Figure 12). Calyptophractus shows an intermediate cranial roof inclination (Figure 12). The outgroups, extant euphractines, and Cabassous (adult) exhibit low values, and the remaining tolypeutines and Peltephilus are even characterized by a negative tilting of IVI (Figure 12).

We propose to treat the IVI angle as a continuous character to scrutinize evolutionary scenarios (see Table 2).

Character 8 (continuous): Internal Vault Inclination.

\section{4 | DISCUSSION}

Due to their very unusual anatomy, even within the Cingulata, the phylogenetic placement of glyptodonts has been long debated (Burmeister, 1874; Carlini \& Zurita, 2010; Fariña et al., 2013; Scott, 1903). Recent molecular analyses have proposed a new hypothesis (i.e., as sister group of the clade tolypeutines + chlamyphorinesDelsuc et al., 2016; Mitchell et al., 2016) at odds with the multiple hypotheses based on morphological analyses (Billet et al., 2011; Engelmann, 1985; Gaudin \& Wible, 2006; Herrera et al., 2017). The recent investigation of the internal anatomy in the Dasypus novemcinctus species complex (Billet et al., 2017) underlined the potential phylogenetic signal hidden in the internal cranial structures of cingulates. Comparative studies on the paranasal sinuses and on brain endocasts of cingulates have been performed but could not provide consistent information on the placement of glyptodonts within the Cingulata (Fernicola et al., 2012; Tambusso \& Fariña, 2015a; Zurita et al., 2011). Our comparative study complements these previous efforts by adding the analysis of the dental alveolar cavities (previously

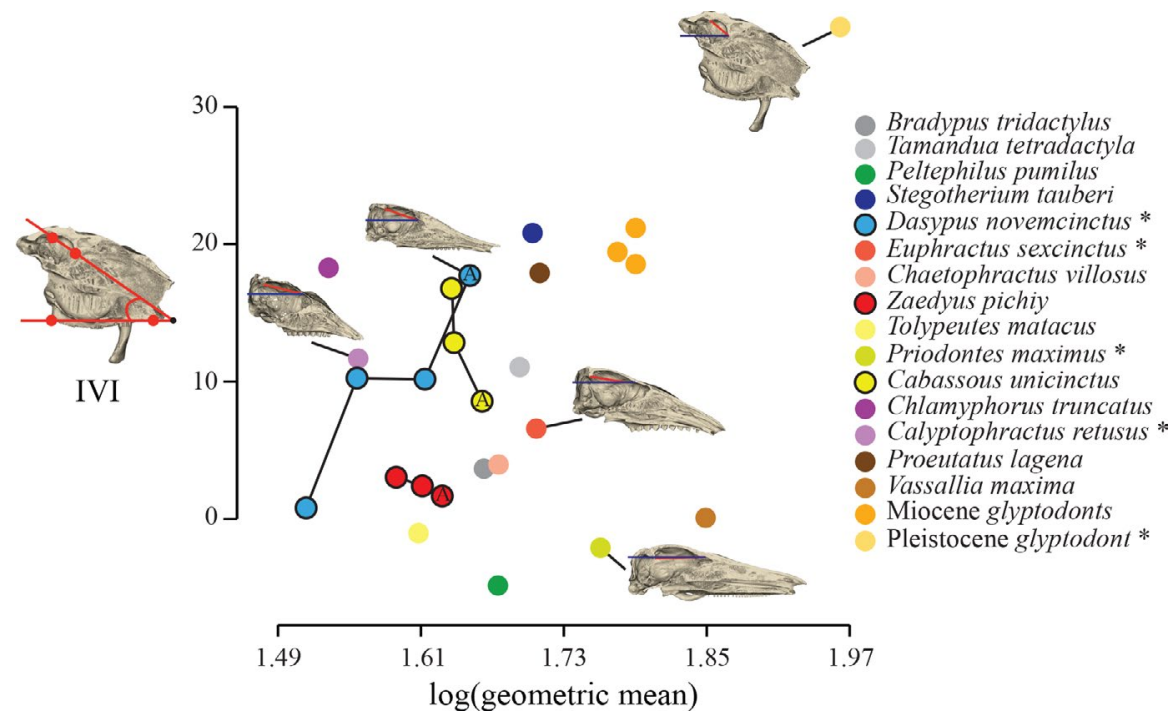

FIGURE 12 Distribution of the internal vault inclination (IVI) with respect to cranial size (= log (geometric mean)) in our sample. For the three developmental series, A symbolizes the adult specimen. Specimens marked with an asterisk are illustrated by cranial reconstructions in sagittal view in the graph. Scale $=1 \mathrm{~cm}$ 
only explored in the glyptodont genus Eucinepeltus by González Ruiz et al., 2020) and of various canals involved in the vascularization and innervation of the cranium (see Wible \& Gaudin, 2004). Based on an extensive sample of extant and extinct cingulates, our survey enabled us to describe many new aspects of the internal cranial anatomy in the group and to propose eight potential characters with helpful phylogenetic information to aid in determining the placement of glyptodonts within Cingulata.

The anatomical variation of the dental alveolar cavities in cingulates comprises many aspects, including the height, curvature, and orientation of teeth, along with their number and distribution on the rostrum (Vizcaíno, 2009). Among our observations, we have proposed two characters with potential bearing on the affinities of glyptodonts. The first corresponds to the position of the most dorsal point of these cavities in lateral view (character 1). The dorsal margins of the alveoli form a dorsally convex line for the whole dental row in most cingulates, except in taxa with reduced teeth. This most dorsal point is situated posteriorly (i.e., at Mf5-6) in Prozaedyus, Zaedyus, chlamyphorines, pampatheres, and glyptodonts in our sample. The distribution of this character would be congruent with the hypothesis of a close relationship between pampatheres and glyptodonts, as suggested by many previous authors (Billet et al., 2011; Gaudin \& Wible, 2006; Herrera et al., 2017; Patterson $\&$ Pascual, 1972), but also supports the clade formed by the latter two with chlamyphorines, as proposed by the morphological analysis of Mitchell et al., (2016) constrained by the molecular backbone (Figure 13). On the other hand, Proeutatus, generally considered to be a close relative of the clade pampatheres + glyptodonts (Billet et al., 2011; Engelmann, 1985; Gaudin \& Lyon, 2017; Gaudin \& Wible, 2006), has its most dorsal point situated much further anteriorly (i.e., ca. Mf1-3).

The second character derived from dental alveolar cavities corresponds to the curvature of the anterior teeth in anterior view (character 2). As for character 1, chlamyphorines and pampatheres resemble glyptodonts in this aspect, exhibiting an inward curvature. Peltephilus, Doellotatus, and also Tolypeutes show a similar condition (Figure 13). As shown by the reconstructed evolutionary scenario (Figure 13), this character could still support the morphological hypothesis of Mitchell et al., (2016) of a close relationship between chlamyphorines and glyptodonts. The distribution of this character on the baseline cladogram shows some homoplasy, however, with the condition in Proeutatus contrasting with that of glyptodonts, while Peltephilus resembles the latter (Figure 13). Another point of interest concerning the variation of dental alveolar cavities is the potential allometric pattern identified by the correlation between the relative height of the dental row and cranium size (Figure 4). This needs to be analyzed further and compared with other allometric patterns seen in the cranium. Mammals generally show an allometric elongation of the rostrum as body size increases, known as craniofacial allometry (Cardini, 2019; Cardini \& Polly, 2013). In Dasypus, this allometric pattern mostly affects the proportions of the rostrum horizontally but less so vertically (Le Verger et al., 2020). The possible allometric increase in the height of the dentition in cingulates thus seems unrelated to craniofacial allometry, but this certainly requires further testing. In addition, we do not know whether allometry could affect the variation of the two aforementioned alveolar cavity characters, but the resemblance of small taxa (i.e., chlamyphorines) and large taxa (i.e., pampatheres and glyptodonts) seems to argue against this. In any case, our study brings to light interesting new variation regarding the upper tooth roots/alveolar cavities of cingulates, which have in the past been compared to one another on the basis of their number, the presence/absence of teeth in the premaxillary, tooth wear, histology, and the orientation of the long axis of the teeth relative to the long axis of the dental row (characters 1, 3-8-Gaudin \& Wible, 2006; see discussion for glyptodonts regarding these characters-Ferigolo, 1985; González Ruiz et al., 2015; Scott, 1903).

Our initial observations on the overall spatial organization of the alveolar cavities point toward a resemblance among chlamyphorines, pampatheres, and glyptodonts, which would be partly compatible with molecular results (Delsuc et al., 2016; Mitchell et al., 2016). However, we believe further information could be gained by more detailed quantified analyses of shape to more fully reflect the complex spatial variation of the dental alveolar cavities.

Our analysis of selected intracranial canals described various aspects of their variation, which were unknown in cingulates until now. Further, it enabled us to propose five characters that provide potentially significant phylogenetic information. This analysis also demonstrated the need to further examine the variation of several structures (e.g., canal of the frontal diploic vein).

Both the trajectory and position of the nasolacrimal canal vary within the sample. A trajectory that is first directed medially at its posterior opening (i.e., the lacrimal foramen) represents a unique characteristic of glyptodonts within the Cingulata (Figures 7 and 8). The most informative feature on this canal regarding the relationships of glyptodonts with other cingulates is the relative height of its anterior opening within the nasal cavity (character 3-Figure 14). In most cingulates, this opening is positioned ventrally in the nasal cavity, close to the hard palate, whereas in glyptodonts, it is near the vertical midpoint of the cavity. The distribution of this character on the baseline cladogram supports the node linking Proeutatus, pampatheres, and glyptodonts (Figure 14), as in several previous morphological analyses (Billet et al., 2011; Engelmann, 1985; Gaudin \& Lyon, 2017; Gaudin \& Wible, 2006).

The course and connection between the sphenopalatine canal and the palatine canal is characterized by a complex pattern which is very peculiar in glyptodonts (Figures S6 and S7). The degree of fusion between the two canals was variable within our sample. Because of taphonomic issues, only "Cochlops" and Glyptodon allowed us to observe a fusion of the two canals in glyptodonts. This fusion was also present in the chlamyphorines. The uncertain condition in Proeutatus and pampatheres does not allow us to draw clear conclusions (character 4-Figure 14), but the distribution of this character on the baseline cladogram could be congruent with the morphological hypothesis of Mitchell et al., (2016) (Figure 14). However, caution is warranted, because the confluence between 
Character 1: Position of the most dorsal point of the dorsal convexity of the tooth row

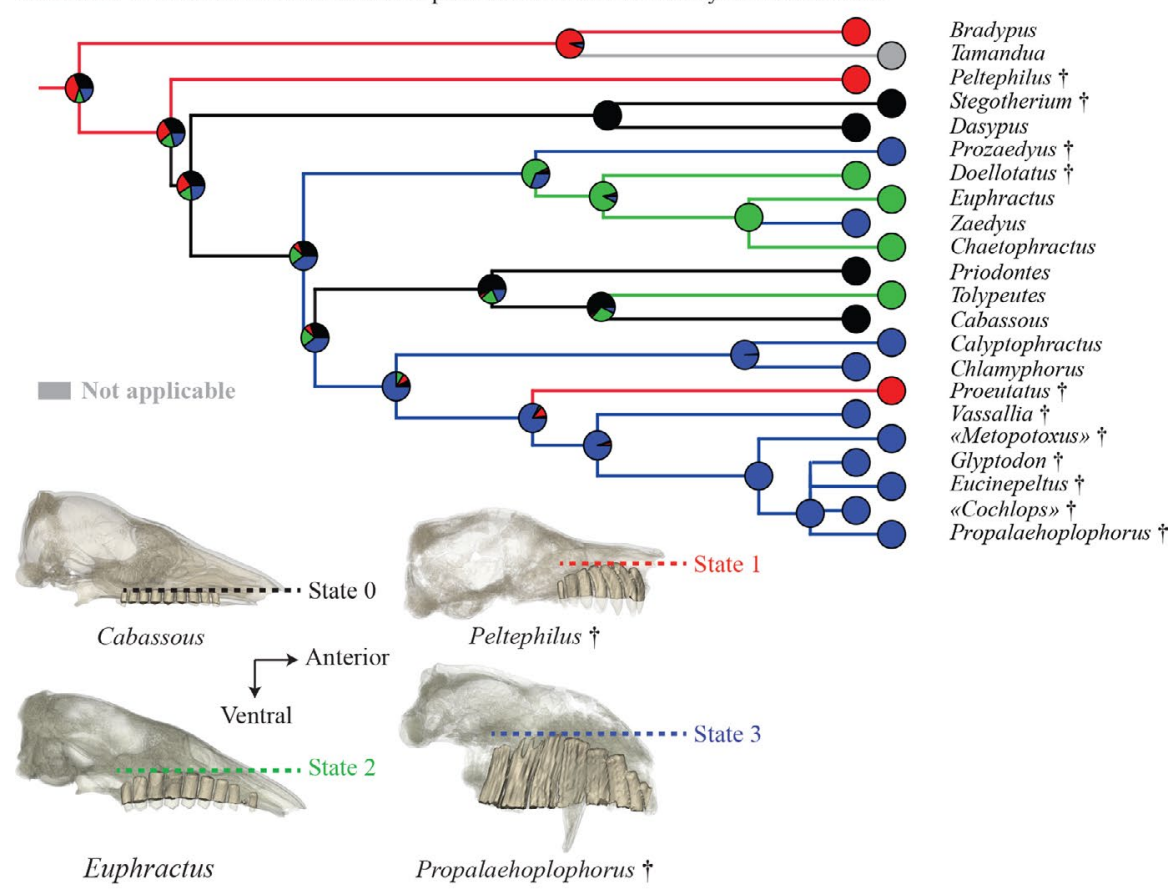

Character 2: Curvature of anterior teeth in anterior view

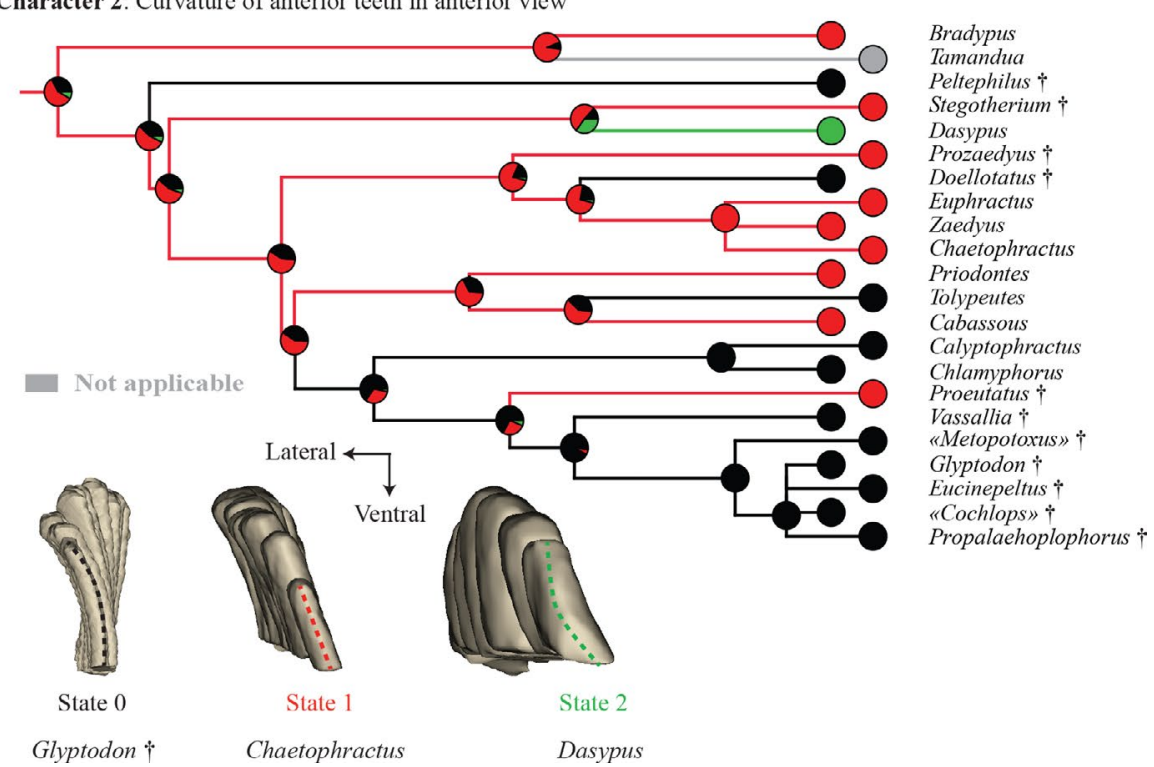

FIGURE 13 Reconstructed evolutionary scenarios for the endocranial characters 1 and 2 plotted on the baseline cladogram with ancestral state estimation for internal nodes (see Materials \& Methods, Data S1 and Figure S3). Each character is illustrated, and the relationship between color and coding is indicated within the figure itself. $\uparrow$ represents extinct genera

the sphenopalatine foramen and the caudal palatine foramen is known to exhibit substantial intraspecific variation in several taxa (see character 71, Gaudin \& Wible, 2006) including Euphractus (see Wible \& Gaudin, 2004). In addition, the condition in pampatheres needs further investigation because a caudal palatine foramen has been identified in the floor of the sphenopalatine canal in Holmesina (see Gaudin \& Lyon, 2017). Our study also reveals a strong resemblance between pampatheres and glyptodonts, which share a dorsal position of the sphenopalatine canal in relation to the nasopharyngeal canal (Figure S7). This feature could have been coded as a character, but an investigation of potential allometry for this trait is required before coding.

The course, orientation, and connections of the transverse canal also vary in our sample. We were unable to identify this canal in Tolypeutes, chlamyphorines, and Glyptodon as well as Bradypus, Peltephilus, and Stegotherium. Its presence in Proeutatus, pampatheres, Miocene glyptodonts and many other cingulates suggests that it has been lost in Glyptodon. Apart from this potential loss, 
Character 3: Opening of the nasolacrimal canal in nasal cavity
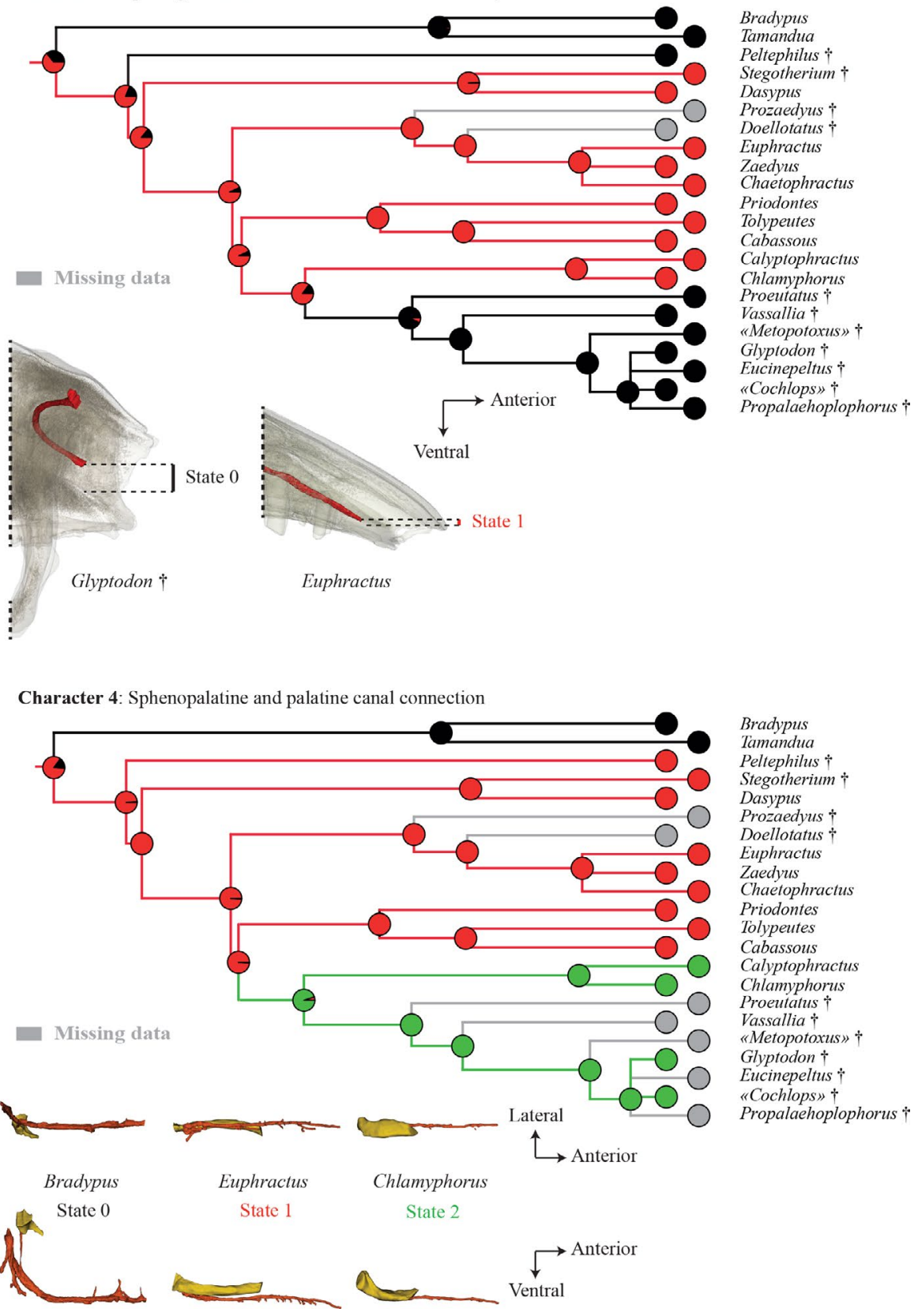

FIGURE 14 Reconstructed evolutionary scenarios for the endocranial characters 3 and 4 plotted on the baseline cladogram with ancestral state estimation for internal nodes (see Materials \& Methods, Data S1 and Figure S3). Each character is illustrated, and the relationship between color and coding is indicated within the figure itself. $\uparrow$ represents extinct genera

the distribution on the baseline cladogram of the character corresponding to the orientation of the branch directly connected to the transverse canal foramen may support the common morphological hypothesis of a close relationship among Proeutatus, pampatheres, and glyptodonts (character 5-Figure 15; see also Billet et al., 2011; Engelmann, 1985; Gaudin \& Wible, 2006; Gaudin \& Lyon, 2017). Moreover, our work is congruent with the matrix of Gaudin and Wible (2006) regarding the presence/absence of the transverse canal foramen for most taxa (character 111) with the exceptions of Tamandua (coded as absent in Gaudin \& Wible, 2006), Stegotherium (coded as present in Gaudin \& Wible, 2006), and Doellotatus. In the case of the latter, the specimen available for our study was poorly preserved for this character (coded as present in Gaudin \& Wible, 2006). Our study also allows us to confirm the hypothesis of Wible and Gaudin (2004), which suggested that the canal crosses the midline of the cranium in Euphractus sexcinctus. In their fetuses, they did not observe this transverse pattern and doubted whether it existed in adult specimens (Wible \& Gaudin, 2004). We can confirm this pattern in our specimen (Figure 9). This circulation pattern is well known in several marsupials, but its putative presence is much less clear in 
Character 5: Orientation of the branch starting from the transverse canal foramen

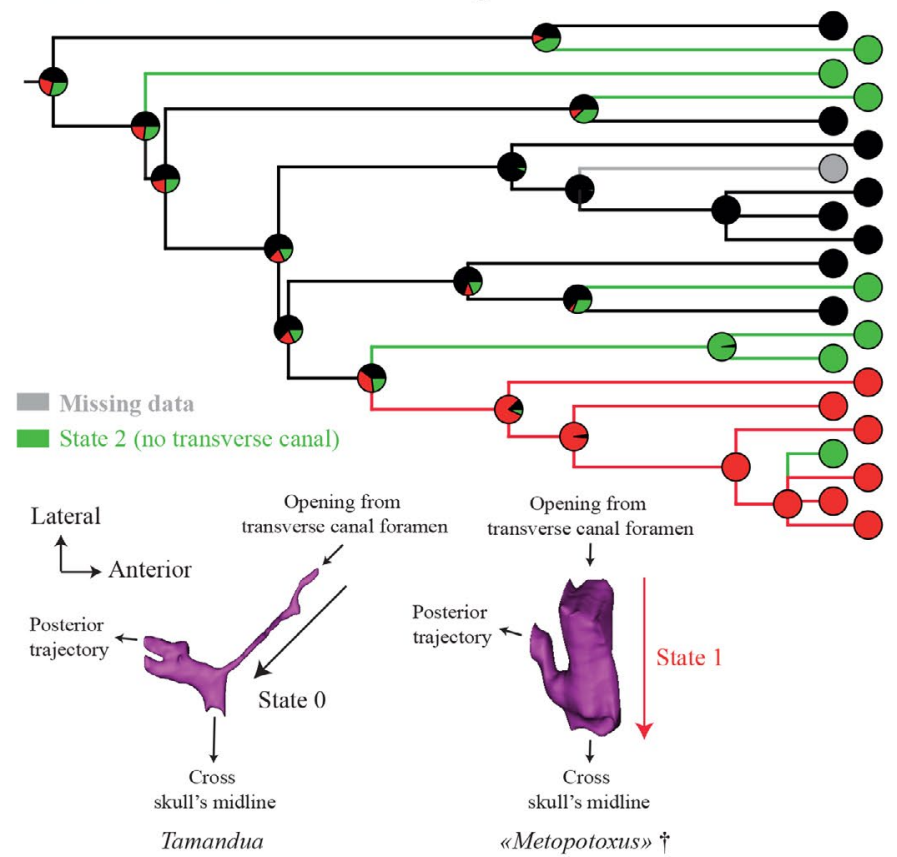

Tamandua

Bradypus

Peltephilus $\uparrow$

Stegotherium $\uparrow$
Dasypus

Prozaedyus $\uparrow$

Doellotatus $\dagger$

Euphractus

Zaedyus

Chaetophractus

Priodontes

Tolypeutes

Cabassous

Calyptophractus

Chlamyphorus

Proeutatus

"Metopotoxus»

Glyptodon †

Eucinepeltus $\uparrow$

"Cochlops" $\dagger$

Propalaehoplophorus †

Character 6: Downward trajectory of the orbitotemporal canal

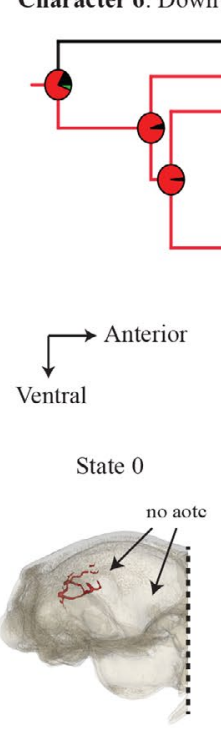

Bradypus
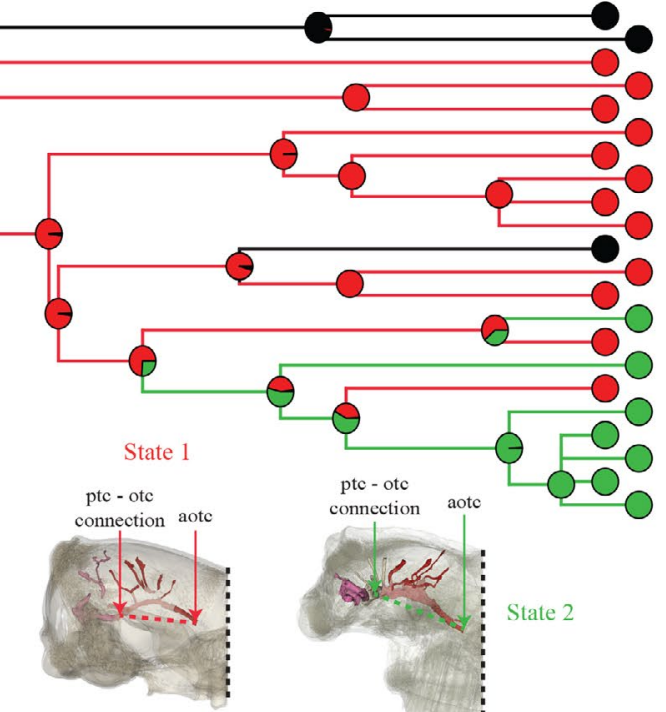

Zaedyus
Tamandua

Bradypus

Peltephilus $\uparrow$

Stegotherium +

Dasypus

Prozaedyus †

Euphractus

Thedus

Chaetophractus

Priodontes

Tolypeutes

Cabassous

Calyptophractus

Chlamyphorus

Proeutatus

«Metopotoxus» †

Glyptodon $\uparrow$

Eucinepeltus

"Cochlops» †

Propalaehoplophorus $\uparrow$

FIGURE 15 Reconstructed evolutionary scenarios for the endocranial characters 5 and 6 plotted on the baseline cladogram with ancestral state estimation for internal nodes (see Materials \& Methods, Data S1 and Figure S3). Each character is illustrated, and the relationship between color and coding is indicated within the figure itself. $\uparrow$ represents extinct genera

placentals, for which the occurrence of a foramen for the transverse canal (often without knowing whether it crosses the cranium midline) is most often interpreted as a case of convergence (Sánchez-Villagra $\&$ Wible, 2002). In addition, our analysis of the youngest specimen of Zaedyus also suggests that the transverse canal is not formed in young euphractine individuals, in accordance with the observations of Wible and Gaudin (2004). However, in young dasypodines, we clearly observe this feature (Figures 3 and 5). For a large majority of taxa in our sample, we can confirm that a transverse canal crossing the midline is present in cingulates.
The distribution on the baseline cladogram of the character corresponding to the anterior course of the orbitotemporal canal also provided interesting information (character 6-Figure 15). Calyptophractus, Proeutatus, and glyptodonts share a strong downward trajectory of this canal, with an anterior opening located much lower in lateral view than its posterior connection of the orbitotemporal canal to the posttemporal canal. The evolutionary scenario for this character is, however, unclear for glyptodonts and their close allies, and homoplasy seems to be present (Figure 15). Our study also highlights the presence of a foramen for the anterior opening of 
Character 7: Canal of the capsuloparietal emissary vein inclination in lateral view

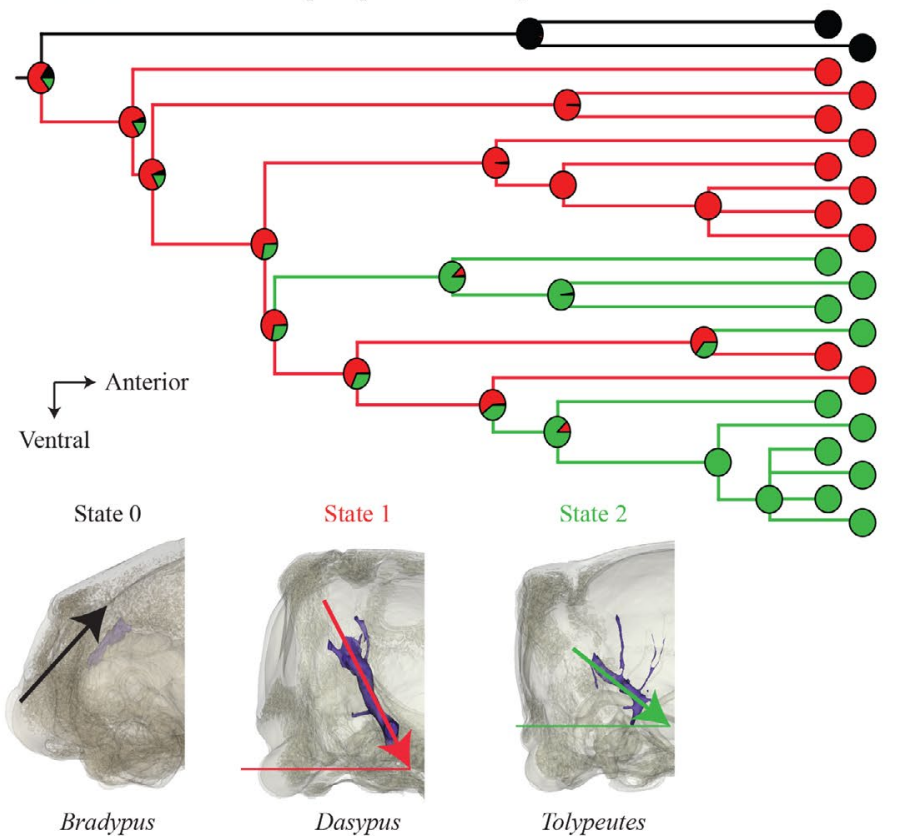

Tamandua

Bradypus

Peltephilus $\dagger$

Stegotherium $\uparrow$

Dasypus

Prozaedyus $\star$

Doellotatus †

Euphractus

Zaedyus

Chaetophractus

Priodontes

Tolypeutes

Cabassous

Calyptophractus

Chlamyphorus

Proeutatus $\dagger$

Vassallia $\uparrow$

"Mlyptodon $\uparrow$

Glyptodon $\dagger$
Eucinepeltus $\uparrow$

«Cochlops» †

Propalaehoplophorus

Bradypus

Dasypus

Tolypeutes

Character 8 (continuous): Internal Vault Inclination

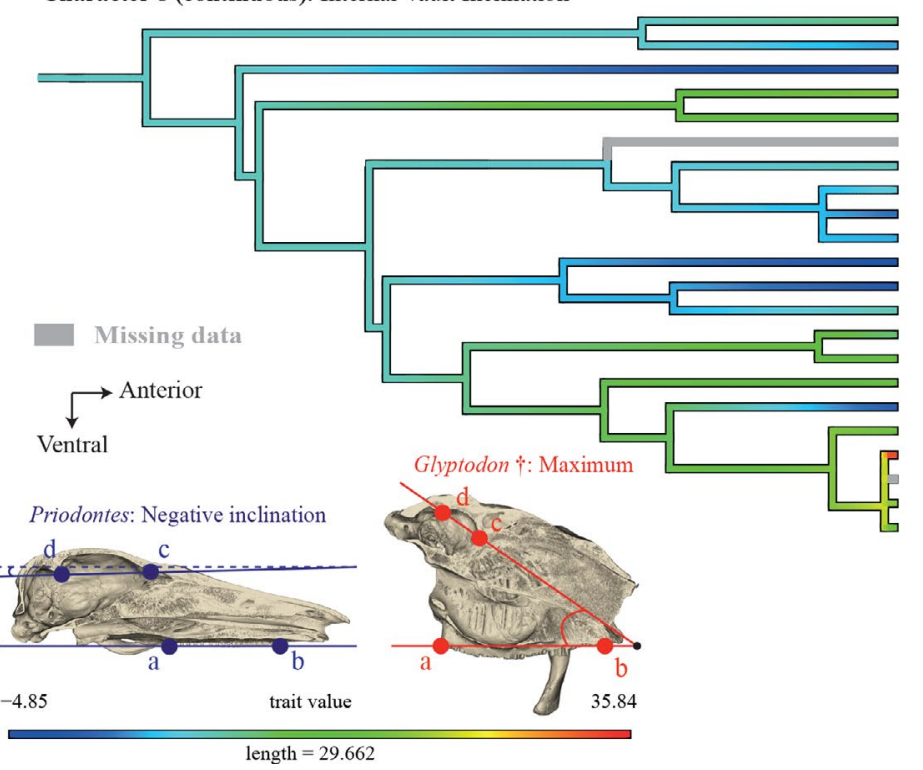

Tamandua

Bradypus

Peltephilus $\dagger$

Stegotherium $\uparrow$

Dasypus

Prozaedyus $\uparrow$

Doellotatus +

Euphractus

Zaedyus

Chaetophractus

Priodontes

Tolypeutes

Cabassous

Calyptophractus

Chlamyphorus

Proeutatus

Vassallia $\uparrow$

"Metopotoxus"

Glyptodon $\uparrow$

Eucinepeltus $\dagger$

"Cochlops" $\uparrow$

Propalaehoplophorus

FIGURE 16 Reconstructed evolutionary scenarios for the endocranial characters 7 and 8 plotted on the baseline cladogram with ancestral state estimation for internal nodes (see Materials \& Methods, Data S1 and Figure S3). Each character is illustrated and the relationship between color and coding is explained within the figure itself. † represents extinct genera. For character 8 (= IVI), the angle between the anteroposterior axis of the cranium (defined by the line connecting the most posterior (a) and anterior (b) edges of the tooth row) and the straight line connecting the most dorsal point of the annular ridge (c) and the most ventral point of the tentorial process (d). Scale $=1$ operator \# $\mathrm{cm}$

the orbitotemporal canal in all cingulates except Priodontes, whereas this foramen was scored as absent in Vassallia and Chlamyphorus in Gaudin and Wible (2006, character 78) and is often unknown for other cingulate taxa. Based on our observation, there is no doubt that the canal opens in the orbitotemporal region in Vassallia, whereas this opening is described as absent in Holmesina floridanus Robertson, 1976 by Gaudin and Lyon (2017). The opposite discrepancy exists regarding the foramen for the frontal diploic vein, absent in Vassallia, and described as present in Holmesina floridanus by Gaudin and Lyon (2017). As these two foramina are usually located relatively close to each other in the orbitotemporal region (a region that itself bears many foramina), we suggest that misidentifications may have occurred between the opening of these two canals, if they are present, or with ethmoidal foramina (Figure S4). The only way to confirm this hypothesis would be to scan Gaudin and Lyon's (2017) specimens of Holmesina floridanus. 
Another character we investigated concerned the inclination of the canal for the capsuloparietal emissary vein in lateral view (character 7-Figure 16). All tolypeutines, Calyptophractus, Vassallia, and glyptodonts share a less steep inclination than that observed in other cingulates, with a part close to the anterior opening oriented almost directly to the anterior direction. The distribution of this character could provide support for the molecular hypothesis of a closer relationship of the glyptodonts with chlamyphorines and tolypeutines (Delsuc et al., 2016; Mitchell et al., 2016; Figure 16). However, the condition is reversed in Chlamyphorus and Proeutatus, creating homoplasy that casts doubt on the evolution of this trait. The trajectory of this canal has never been scored in prior phylogenetic analyses of the Cingulata. In the literature, only two characters have been scored that indirectly concern this canal, characters 119 and 120 of Gaudin and Wible (2006), related to the presence/absence of the postglenoid foramen and suprameatal foramen, respectively. These characters deliver contrasting groupings among cingulates (Gaudin \& Wible, 2006).

Finally, the internal inclination of the cranial vault relative to the anteroposterior axis of the cranium also helps identify some cingulate taxa that may resemble glyptodonts in this regard (character 8; Figure 16). The distribution of this quantitative trait on the baseline cladogram indicates that the dasypodines, chlamyphorines, Proeutatus, and glyptodonts exhibit a strong IVI angle, whereas Vassallia possesses a very weak angle. This strong difference between glyptodonts and pampatheres was already highlighted by Tambusso and Fariña (2015b). The variation of this trait was not explained by allometry in our sample. A highly inclined vault may have been evolved independently in the dasypodines and in glyptodonts and their allies. Its distribution could provide support for a relationship among chlamyphorines, Proeutatus, and glyptodonts to the exclusion of pampatheres or the latter may have undergone a reversal (Figure 16). The vault inclination in these taxa seems to be partly congruent with the distribution of a character proposed by Billet et al., (2011) and discussed by Delsuc et al., (2016), that is, the dorsal position of the ventral surface of the auditory region relative to the palate (character 78-Billet et al., 2011). This is a characteristic of chlamyphorines, eutatines, pampatheres, and glyptodonts in Billet et al., (2011)'s analysis. The potential relationship of these two aspects of the braincase should be tested in future studies.

In conclusion, our investigation of the cranial canals and alveolar cavities highlighted several endocranial characters that support a resemblance of glyptodonts with chlamyphorines, Proeutatus, and pampatheres. Except for character 7, our investigation did not bring to light new, and strong resemblances between tolypeutines and glyptodonts that would support their close relationship as suggested by molecular studies (Delsuc et al., 2016; Mitchell et al., 2016). In short, our study of internal anatomy lends further credence to recent reports of a greater morphological resemblance between glyptodonts and chlamyphorines than tolypeutines (Delsuc et al., 2016; Mitchell et al., 2016). In this regard, it is worth noting that the chlamyphorines + tolypeutines relationship received distinctly lower statistical support than most other clades in mitogenomic analyses of cingulate phylogeny (Delsuc et al., 2016; Mitchell et al., 2016).
The congruence of these new internal characters with past morphological phylogenetic analyses of the group is difficult to evaluate since the results of the latter have been rather unstable (e.g., Abrantes \& Bergqvist, 2006; Billet et al., 2011; Engelmann, 1985; Gaudin \& Wible, 2006). However, a close resemblance of glyptodonts to the eutatine Proeutatus and the pampatheres is supported by several characters in our study, which would be congruent with several recent phylogenetic hypotheses based on morphological data (Billet et al., 2011; Engelmann, 1985; Gaudin \& Lyon, 2017; Gaudin \& Wible, 2006). More generally, internal cranial anatomy seems to show similarities among chlamyphorines, Proeutatus, pampatheres, and glyptodonts (see also Tambusso et al., 2021), but new analyses are needed that incorporate this new data before firmer phylogenetic conclusions can be reached. Our study provides a nonexhaustive account of internal canals of the cranium. Internal structures still need to be studied to select new characters, in particular for endocranial traits that we briefly describe but do not explore in detail. This is notably the case with the canal for the frontal diploic vein or the position of the sphenopalatine canal in relation to the nasopharyngeal canal, whose patterns of variation remain unclear at the moment. Another promising way forward was also revealed by our developmental series, in which Cabassous varies in a manner different from that of Dasypus and Zaedyus as far as the inclination of the cranial roof is concerned (Figure 12). A better exploration of the developmental series with more specimens per species and more species sampled could provide a better understanding of their ontogenetic trajectories, which could then be coded for phylogenetic analyses (e.g., Bardin et al., 2017). Further studies are also needed to better understand the patterns of variation of the internal characters highlighted here, which in some respects may be affected by allometry, as we have highlighted for alveolar cavities and for the canal for the capsuloparietal emissary vein.

\section{ACKNOWLEDGMENTS}

We are grateful to Christiane Denys, Violaine Nicolas, and Géraldine Véron, (Muséum National d'Histoire Naturelle, Paris, France); Roberto Portela Miguez, Louise Tomsett, and Laura Balcells (British Museum of Natural History, London, UK); Neil Duncan, Eileen Westwig, Eleanor Hoeger, Ross MacPhee, Marisa Surovy, and Morgan Hill Chase (American Museum of Natural History, New York, USA); Nicole Edmison and Chris Helgen (National Museum of Natural History, Washington, DC, USA); Jake Esselstyn (Louisiana State University, Museum of Natural Sciences, Baton Rouge, USA); Manuel Ruedi (Muséum d'Histoire Naturelle, Geneva, Switzerland); Pepijn Kamminga, Arjen Speksnijder, and Rob Langelaan (Naturalis Biodiversity Center, Leiden, Holland); April Isch and Zhe-Xi Luo (University of Chicago, Chicago, USA); Adrienne Stroup and Bill Simpson (Field Museum of Natural History, Chicago, USA); Steffen Bock, Christiane Funk, Frieder Mayer, Anna Rosemann, Lisa Jansen, Kristin Mahlow, Johannes Müller, and Eli Amson (Museum für Naturkunde, Berlin, Germany); and Camille Grohé (University of Poitiers, Poitiers, France) for access to comparative material and/or to CT scans. We would like 
to warmly thank Daniel Brinkmann (Yale Peabody Museum, New Haven, USA) for his precious help in organizing KLV's visit to the collections of the Yale Peabody Museum. Many thanks also to Sergio Ferreira-Cardoso (Institut des Sciences de l'Evolution) for his help with data acquisition during the trips of KLV. We thank Benoit de Thoisy (Institut Pasteur de la Guyane) and Clara Belfiore for their help with data acquisition, Olivia Plateau (University of Fribourg, Switzerland) for her help on the R script, and Cyril Le Verger for his help with segmentation. We thank Renaud Lebrun (Institut des Sciences de l'Evolution), Farah Ahmed (British Museum of Natural History), Miguel García-Sanz, Marta Bellato, Nathalie Poulet, and Florent Goussard (Platform AST-RXMuséum National d'Histoire Naturelle) who generously provided help with CT scanning. We would like to warmly thank Christian de Muizon (Centre de Recherche en Paléontologie-Paris), Timothy Gaudin (University of Tennessee), Robert J. Asher (University of Cambridge), Sophie Montuire (University of Bourgogne), Isabelle Rouget (Centre de Recherche en Paléontologie-Paris), Allowen Evin and Lionel Hautier (Institut des Sciences de l'Evolution) for reviewing a previous version of this work in the $\mathrm{PhD}$ dissertation of KLV. Finally, we thank the two anonymous reviewers for their corrections and comments that helped us improve our manuscript. Some of the analyses were performed using the $\mu$-CT facilities of the Montpellier Rio Imaging (MRI) platform of the LabEx CeMEB. KLV acknowledges the financial support provided by the Sorbonne Universities/ED227 transhumance international grant program. In addition, the authors declare that they have no conflicts of interest.

\section{AUTHOR CONTRIBUTIONS}

KLV contributed to data acquisition, data analyses/interpretations, drafting of the manuscript, and study design. LGR contributed to data acquisition and critical revision of the manuscript. GB contributed to data acquisition, study design, and critical revision of the manuscript.

\section{DATA AVAILABILITY STATEMENT}

A large part of specimens scanned will be available on MorphoMuseum for 3D models and on MorphoSource for scans. Specimens scanned by LGR will be available upon request to LGR. The list of specimens is given in Table S2.

\section{ORCID}

Kévin Le Verger (D) https://orcid.org/0000-0001-8498-7372

\section{REFERENCES}

Abba, A.M., Cassini, G.H., Valverde, G. et al. (2015) Systematics of hairy armadillos and the taxonomic status of the Andean hairy armadillo (Chaetophractus nationi). Journal of Mammalogy, 96(4), 673-689.

Abrantes, E.A.L. \& Bergqvist, L.P. (2006) Proposta filogenetica para os Dasypodidae (Mammalia: Cingulata). In: Gallo, V., Brito, P.M., Silva, H.M.A. \& Figueirido, F.J. (Eds.) Paleontologia Vertebrados: Grandes Temas e Contribuiçoes Científicas. Rio de Janeiro: Interciências. pp. 261-274.
Ameghino, F. (1884) Filogenia: Principios de Clasificación Transformista Basados Sobre Leyes Naturales y Proporciones Matemáticas. Buenos Aires: Lajouane, F.

Ameghino, F. (1887) Enumeración sistemática de las especies de mamíferos fósiles coleccionados por Carlos Ameghino en los terrenos eocenos de Patagonia austral y depositados en el Museo La Plata. Extracto del Boletín del Museo La Plata, 1, 1-26.

Ameghino, F. (1889) Contribución al conocimiento de los mamíferos fósiles de la República Argentina. Actas de la Academia Nacional de Ciencias en Córdoba, 6, 1-1027.

Ameghino, F. (1891) Nuevos restos de mamíferos fósiles descubiertos por Carlos Ameghino en el Eoceno inferior de la Patagonia austral. Especies nuevas, adiciones y correcciones. Revista Argentina de Historia Natural, 1, 289-328.

Bardin, J., Rouget, I. \& Cecca, F. (2017) Ontogenetic data analyzed as such in phylogenies. Systematic Biology, 66(1), 23-37.

Billet, G., Hautier, L., de Muizon, C. \& Valentin, X. (2011) Oldest cingulate skulls provide congruence between morphological and molecular scenarios of armadillo evolution. Proceedings of the Royal Society B: Biological Sciences, 278(1719), 2791-2797.

Billet, G., Hautier, L., de Thoisy, B. \& Delsuc, F. (2017) The hidden anatomy of paranasal sinuses reveals biogeographically distinct morphotypes in the nine-banded armadillo (Dasypus novemcinctus). PeerJ, 5, e3593.

Billet, G., Hautier, L. \& Lebrun, R. (2015) Morphological diversity of the bony labyrinth (inner ear) in extant xenarthrans and its relation to phylogeny. Journal of Mammalogy, 96(4), 658-672.

Boddaert, P. (1768) Dierkundig Mengelwerk in Het Welke de Nieuwe of nog Duistere Zoorten Van Dieren. Utrecht: Abraham van Paddenburg en J. Van Schoonhoven (Volume 2).

Bollback, J.P. (2006) SIMMAP: Stochastic character mapping of discrete traits on phylogenies. BMC Bioinformatics, 7(1), 1-7.

Bordas, A.F. (1932) Proposición de un nuevo género para "Eutatus inornatus". Physis, 11(38), 167-168.

Boscaini, A., lurino, D.A., Mamani Quispe, B., Andrade Flores, R., Sardella, R., Pujos, F. \& et al. (2020) Cranial anatomy and paleoneurology of the extinct sloth Catonyx tarijensis (Xenarthra, Mylodontidae) from the late Pleistocene of Oruro, Southwestern Bolivia. Frontiers in Ecology and Evolution, 8, 1-16.

Boscaini, A., lurino, D.A., Sardella, R., Tirao, G., Gaudin, T.J. \& Pujos, F. (2018) Digital cranial endocasts of the extinct sloth Glossotherium robustum (Xenarthra, Mylodontidae) from the late Pleistocene of Argentina: description and comparison with the extant sloths. Journal of Mammalian Evolution, 27(1), 55-71.

Burmeister, H. (1863) Ein neuer Chlamyphorus. Abhandlungen Naturforschende Gesellschaft zu Halle, 7, 165-171.

Burmeister, H. (1874) Monografía de los glyptodontes en el Museo Público de Buenos Aires. Anales del Museo Público de Buenos Aires, 2, 1-412.

Cardini, A. (2019) Craniofacial allometry is a rule in evolutionary radiations of placentals. Evolutionary Biology, 46(3), 239-248.

Cardini, A. \& Polly, P.D. (2013) Larger mammals have longer faces because of size-related constraints on skull form. Nature Communications, 4(1), 1-7.

Carlini, A.A., Soibelzon, E. \& Glaz, D. (2016) Chaetophractus vellerosus (Cingulata: Dasypodidae). Mammalian Species, 48(937), 73-82.

Carlini, A.A. \& Zurita, A.E. (2010) An introduction to cingulate evolution and their evolutionary history during the great American biotic interchange: Biogeographical clues from Venezuela. In: Sánchez-Villagra, M., Aguilera, O. \& Carlini, A.A. (Eds.) Urumaco and Venezuela paleontology. The fossil record of the northern neotropics. Bloomington: Indiana University Press, pp. 233-255.

Castellanos, A. (1932) Nuevos géneros de gliptodontes en relación con su filogenia. Physis, 11(38), 92-100. 
Castellanos, A. (1946) Un nuevo gliptodontoideo del Araucanense del valle de Yocavil (Santa María) de la Provincia de Tucumán. Publicaciones del Instituto de Fisiografía y Geología, 6, 1-19.

Castellanos, A. (1959) Trascendencia de la obra de Florentino Ameghino. Revista de la Facultad de Ciencias Naturales de Salta, 1, 35-56.

Ciancio, M.R., Castro, M.C., Galliari, F.C., Carlini, A.A. \& Asher, R.J. (2012) Evolutionary implications of dental eruption in Dasypus (Xenarthra). Journal of Mammalian Evolution, 19(1), 1-8.

Claude, J. (2008) Morphometrics with R. New York: Springer-Verlag.

Clavel, J., Escarguel, G. \& Merceron, G. (2015) mvMORPH: An R package for fitting multivariate evolutionary models to morphometric data. Methods in Ecology and Evolution, 6(11), 1311-1319.

Clavel, J., Merceron, G. \& Escarguel, G. (2014) Missing Data Estimation in Morphometrics: How Much is Too Much? Systematic Biology, 63(2), 203-218.

Cuvier, G. (1798) Tableau élémentaire de l'histoire naturelle des animaux. Paris: Baudouin.

de Muizon, C., Billet, G., Argot, C., Ladevèze, S. \& Goussard, F. (2015) Alcidedorbignya inopinata, a basal pantodont (Placentalia, Mammalia) from the early Palaeocene of Bolivia: Anatomy, phylogeny and palaeobiology. Geodiversitas, 37(4), 397-634.

de Muizon, C. \& Marshall, L.G. (1987) Le plus ancien Pantodonte (Mammalia) du Crétacé supérieur de Bolivie. Comptes rendus hebdomadaires des Séances de l'Académie des Sciences, Paris, 304, 205-208.

Delsuc, F., Gibb, G.C., Kuch, M., Billet, G., Hautier, L., Southon, J. et al. (2016) The phylogenetic affinities of the extinct glyptodonts. Current Biology, 26(4), 155-156.

Desmarest, A.G. (1804) Tableau méthodique des mammifères. Nouveau Dictionnaire d'Histoire Naturelle, 24, 5-58.

Engelmann, G.F. (1985) The phylogeny of the Xenarthra. In: Montgomery, G.G. (Ed.) The Evolution and Ecology of Armadillos, Sloths and Vermilinguas. Washington: Smithsonian Institution Press, pp. 51-64.

Evans, H.E. \& De Lahunta, A. (2012) Miller's Anatomy of the Dog. St Louis: Saunders.

Fariña, R.A., Vizcaíno, S.F. \& De luliis, G. (2013) Megafauna: Giant Beasts of Pleistocene South America. Bloomington: Indiana University Press.

Ferigolo, J. (1985) Evolutionary trends of the histological pattern in the teeth of Edentata (Xenarthra). Archives of Oral Biology, 30(1), 71-82.

Fernicola, J.C. (2008) Nuevos aportes para la sistemática de los Glyptodontia Ameghino 1889 (Mammalia, Xenarthra, Cingulata). Ameghiniana, 45(3), 553-574.

Fernicola, J.C., Rinderknecht, A., Jones, W., Vizcaíno, S.F. \& Porpino, K. (2017) A new species of Neoglyptatelus (Mammalia, Xenarthra, Cingulata) from the late Miocene of Uruguay provides new insights on the evolution of the dorsal armor in cingulates. Ameghiniana, 55(3), 233-252.

Fernicola, J.C., Toledo, N., Bargo, M.S. \& Vizcaíno, S.F. (2012) A neomorphic ossification of the nasal cartilages and the structure of paranasal sinus system of the glyptodont Neosclerocalyptus Paula Couto 1957 (Mammalia, Xenarthra). Palaeontologia Electronica, 15, 1-22.

Flower, W.H. (1882) On the mutual affinities of the animals composing the order Edentata. Proceeding of the Zoological Society of London, $50,358-367$.

Gaudin, T.J. (1995) The ear region of edentates and the phylogeny of the Tardigrada (Mammalia, Xenarthra). Journal of Vertebrate Paleontology, 15(3), 672-705.

Gaudin, T.J. (2004) Phylogenetic relationships among sloths (Mammalia, Xenarthra, Tardigrada): The craniodental evidence. Zoological Journal of the Linnean Society, 140(2), 255-305.

Gaudin, T.J. \& Lyon, L.M. (2017) Cranial osteology of the pampathere Holmesina floridanus (Xenarthra: Cingulata; Blancan NALMA), including a description of an isolated petrosal bone. PeerJ, 5, e4022.

Gaudin, T.J. \& Wible, J.R. (2006) The phylogeny of living and extinct armadillos (Mammalia, Xenarthra, Cingulata): a craniodental analysis. In: Carrano, M.T., Gaudin, T.J., Blob, R.W., \& Wible, J.R. (Eds.) Amniote
Paleobiology: Perspectives on the Evolution of Mammals, Birds, and Reptiles. Chicago: University of Chicago Press, pp. 153-198.

González Ruiz, L., Aya-Cuero, C.A. \& Martin, G.M. (2017) La dentición de Priodontes maximus (Kerr, 1972): formula, morfología y anomálias. XXVII Jornadas Argentinas de Mastozoología. 14 al 17 de Noviembre de 2017. Bahía Blanca (Buenos Aires), Argentina. Libro de Resúmenes: 135.

González Ruiz, L.R., Brandoni, D., Zurita, A.E., Green, J.L., Novo, N.M., Tauber, A.A. \& et al. (2020) Juvenile glyptodont (Mammalia, Cingulata) from the Miocene of Patagonia, Argentina: Insights into mandibular and dental characters. Journal of Vertebrate Paleontology, 40(1), e1768398.

González Ruiz, L., Ciancio, M.R., Martin, G.M. \& Zurita, A.E. (2015) First record of supernumerary teeth in Glyptodontidae (Mammalia, Xenarthra, Cingulata). Journal of Vertebrate Paleontology, 35(1), e885033.

González Ruiz, L., Ladevèze, S. \& MacPhee, R.D. (2014) Dental anomalies in Euphractus sexcinctus Wagler (Mammalia: Xenarthra: Dasypodidae). 94th Annual Meeting of the American Society of Mammalogists. 6 al 10 de Junio de 2014. Oklahoma City (Oklahoma), USA. Abstract Book: 59-60.

González Ruiz, L. \& MacPhee, R.D. (2014) Dental anomalies in Tolypeutes matacus (Desmarest, 1804) (Mammalia, Xenarthra, Cingulata). XXVII Jornadas Argentinas de Mastozoología. 4 al 7 de Noviembre de 2014. Esquel (Chubut), Argentina. Libro de Resúmenes: 94.

González Ruiz, L. \& Scilalto-Yané, G.J. (2008) Una nueva especie de Stegotherium Ameghino (Xenarthra, Dasypodidae, Stegotheriini) del Mioceno de la provincia de Santa Cruz (Argentina). Ameghiniana, 45(4), 641-648.

Harlan, R. (1825) Description of a new genus of mammiferous quadrupeds of the Order Edentata. Annals of the Lyceum of Natural History of New York, 6, 235-246.

Hayssen, V. (2014) Cabassous unicinctus (Cingulata: Dasypodidae). Mammalian Species, 46(907), 16-23.

Herrera, C.M.R., Powell, J.E., Esteban, G.I. \& Del Papa, C. (2017) A new Eocene dasypodid with caniniforms (Mammalia, Xenarthra, Cingulata) from northwest Argentina. Journal of Mammalian Evolution, 24(3), 275-288.

Hoffstetter, R. (1958) Xenarthra. In: de Paléontologie, T. (Ed.) Piveteau, J. Paris: Masson \& Cie.

Huxley, T.H. (1864) II. On the osteology of the genus Glyptodon. Philosophical Transactions of the Royal Society of London, 155, 31-70.

Kerr, R. (1792) The animal kingdom or zoological system, of the celebrated Sir Charles Linnaeus. Class I. Mammalia: Contain a complete systematic description, arrangement, and nomenclature, of all the known species and varieties of mammalia, or animals which give suck to their young; being a translation of that part of the systema naturae, as lately published, with great improvements, by professor gmelin of goettingen, together with numerous additions from more recent zoological writers, and illustrated with copperplates. London/Edinburgh: Strahan, A., Cadell, T. \& Creech, W. (Eds).

Le Verger, K., Hautier, L., Bardin, J., Gerber, S., Delsuc, F. \& Billet, G. (2020) Ontogenetic and static allometry in the skull and cranial units of nine-banded armadillos (Cingulata: Dasypodidae: Dasypus novemcinctus). Biological Journal of the Linnean Society, 131(3), 673-698.

Linnæus, C. (1758) Systema naturae per regna tria. Naturæ, secundum classes, ordines, genera, species, cum characteribus, differentiis, synonymis, locis. Tomus I. Editio decima, reformata. Homiae: Laurentii Salvii.

McBee, K. \& Baker, R.J. (1982) Dasypus novemcinctus. Mammalian Species, 162, 1-9.

Messineo, P.G. \& Politis, G.G. (2009) New radiocarbon dates from the Campo Laborde site (Pampean Region, Argentina) support the Holocene survival of giant ground sloth and glyptodonts. Current Research in the Pleistocene, 26, 5-9. 
Mitchell, K.J., Scanferla, A., Soibelzon, E., Bonini, R., Ochoa, J. \& Cooper, A. (2016) Ancient DNA from the extinct South American giant glyptodont Doedicurus sp. (Xenarthra: Glyptodontidae) reveals that glyptodonts evolved from Eocene armadillos. Molecular Ecology, 25(14), 3499-3508.

Owen, R. (1839). Description of a tooth and part of the skeleton of the Glyptodon, a large quadruped of the edentate order, to which belongs the tessellated bony armour figured by Mr. Clift in his memoir on the remains of the Megatherium, brought to England by Sir Woodbine Parish, F.G.S. Proceedings of the Geological Society of London, 3, 108-113.

Paradis, E. \& Schliep, K. (2019) ape 5.0: an environment for modern phylogenetics and evolutionary analyses in R. Bioinformatics, 35(3), 526-528.

Patterson, B. \& Pascual, R. (1972) The fossil mammal fauna of South America. In: Keast, A., Erk, F.C. \& Glass, B. (Eds.) Evolution, Mammals, and Southern Continents. Albany: State University of New York Press, pp. 247-309.

Patterson, B., Segall, W. \& Turnbull, W.D. (1989) The ear region in xenarthrans (=Edentata, Mammalia). Part I. Cingulates. Fieldiana Geology, 18, $1-46$.

Porpino, K.D.O., Fernicola, J.C. \& Bergqvist, L.P. (2010) Revisiting the intertropical Brazilian species Hoplophorus euphractus (Cingulata, Glyptodontoidea) and the phylogenetic affinities of Hoplophorus. Journal of Vertebrate Paleontology, 30(3), 911-927.

Revell, L.J. (2012) phytools: A R package for phylogenetic comparative biology (and other things). Methods in ecology and Evolution, 3(2), 217-223.

Robertson, J.S. (1976) Latest Pliocene mammals from Haile XV A, Alachua County, Florida. Bulletin of the Florida State Museum, Biological Sciences, 20(3), 111-186.

Sánchez-Villagra, M.R. \& Wible, J.R. (2002) Patterns of evolutionary transformation in the petrosal bone and some basicranial features in marsupial mammals, with special reference to didelphids. Journal of Zoological Systematics and Evolutionary Research, 40(1), 26-45.

Scott, W.B. (1903) Mammalia of the Santa Cruz beds. I. Edentata. Reports of the Princeton University Expeditions to Patagonia. Princeton/ Stuttgart: Princeton University.

Simpson, G.G. (1930) Holmesina septentrionalis, extinct giant armadillo of Florida. American Museum Novitates, 422, 1-10.

Smith, P. \& Owen, R.D. (2017) Calyptophractus retusus (Cingulata: Dasypodidae). Mammalian Species, 49(947), 57-62.

Superina, M. \& Loughry, W.J. (2015) Why do Xenarthrans matter? Journal of Mammalogy, 96(4), 617-621.

Swofford, D.L.. (2002) PAUP: Phylogenetic analysis using parsimony (and other methods). Version 4.0a167. Sunderland: Sinauer Associates.

Tambusso, P.S. \& Fariña, R.A. (2015a) Digital cranial endocast of Pseudoplohophorus absolutus (Xenarthra, Cingulata) and its systematic and evolutionary implications. Journal of Vertebrate Paleontology, 35(5), e967853.

Tambusso, P.S. \& Fariña, R.A. (2015b) Digital endocranial cast of Pampatherium humboldtii (Xenarthra, Cingulata) from the Late Pleistocene of Uruguay. Swiss Journal of Palaeontology, 134(1), 109-116.

Tambusso, P.S., Varela, L., Góis, F., Moura, J.F., Villa, C. \& Fariña, R.A. (2021) The inner ear anatomy of glyptodonts and pampatheres
(Xenarthra, Cingulata): Functional and phylogenetic implications. Journal of South American Earth Sciences, 108, 103189.

Thewissen, J.G.M. (1989) Mammalian frontal diploic vein and the human foramen caecum. The Anatomical Record, 223(2), 242-244.

Vizcaíno, S.F. (2009) The teeth of the "toothless": novelties and key innovations in the evolution of xenarthrans (Mammalia, Xenarthra). Paleobiology, 35(3), 43-366.

Vizcaíno, S.F. \& Loughry, W.J. (2008) Biology of the Xenarthra. Gainesville: University Press of Florida.

Wake, D.B., Wake, M.H. \& Specht, C.D. (2011) Homoplasy: from detecting pattern to determining process and mechanism of evolution. Science, 331(6020), 1032-1035.

Wetzel, R.M. (1985) Taxonomy and distribution of armadillos, Dasypodidae. In: Montgomery, G.G. (Ed.) The Evolution and Ecology of Armadillos, Sloths, and Vermilinguas. Washington DC: Smithsonian Institution Press, pp. 23-46.

Wetzel, R.M., Gardner, A.L., Redford, K.H. \& Eisenberg, J.F. (2007) Order Cingulata. In: Gardner, A.L. (Ed.) Mammals of South America: Marsupials, Xenarthrans, Shrews, and Bats. Chicago: University of Chicago Press, pp. 128-156.

Wible, J.R. (1987) The eutherian stapedial artery: character analysis and implications for superordinal relationships. Zoological Journal of the Linnean Society, 91(2), 107-135.

Wible, J.R. (1993) Cranial circulation and relationships of the colugo Cynocephalus (Dermoptera, Mammalia). American Museum Novitates, 3072, 1-27.

Wible, J.R. (2010) Petrosal anatomy of the nine-banded armadillo, Dasypus novemcinctus Linnaeus, 1758 (Mammalia, Xenarthra, Dasypodidae). Annals of the Carnegie Museum, 79(1), 1-28.

Wible, J.R. \& Gaudin, T.J. (2004) On the cranial osteology of the yellow armadillo Euphractus sexcintus (Dasypodidae, Xenarthra, Placentalia). Annals of the Carnegie Museum, 73(3), 1-117.

Wible, J.R. \& Spaulding, M. (2013) On the cranial osteology of the African palm civet, Nandinia binotata (Gray, 1830) (Mammalia, Carnivora, Feliformia). Annals of the Carnegie Museum, 82(1), 1-114.

Zurita, A.E., Scarano, A.C., Carlini, A.A., Scillato-Yané, G.J. \& Soibelzon, E. (2011) Neosclerocalyptus spp. (Cingulata: Glyptodontidae: Hoplophorini): Cranial morphology and palaeoenvironments along the changing Quaternary. Journal of Natural History, 45(15-16), 893-914.

\section{SUPPORTING INFORMATION}

Additional supporting information may be found online in the Supporting Information section.

How to cite this article: Le Verger, K., González Ruiz, L.R.\&Billet, G. (2021) Comparative anatomy and phylogenetic contribution of intracranial osseous canals and cavities in armadillos and glyptodonts (Xenarthra, Cingulata). Journal of Anatomy, 00, 1-30. https://doi.org/10.1111/joa.13512 